\title{
EXTRATABILIDADE DO CÁDMIO: INFLUÊNCIA DE ATRIBUTOS DE SOLOS MUITO INTEMPERIZADOS EM EXTRATORES CONVENCIONAIS E POTENCIALIDADE DE ÁCIDOS ORGÂNICOS DE BAIXO PESO MOLECULAR
}

\section{MICHELLE BORGES}

\begin{abstract}
Dissertação apresentada à Escola Superior de Agricultura "Luiz de Queiroz", Universidade de São Paulo, para obtenção do título de Mestre em Agronomia, Área de Concentração: Solos e Nutrição de Plantas.
\end{abstract}

\author{
$P \mid R A C I C A B A$ \\ Estado de São Paulo - Brasil \\ Janeiro - 2002
}




\section{EXTRATABILIDADE DO CÁDMIO: INFLUÊNCIA DE ATRIBUTOS DE SOLOS MUITO INTEMPERIZADOS EM EXTRATORES CONVENCIONAIS E POTENCIALIDADE DE ÁCIDOS ORGÂNICOS DE BAIXO PESO MOLECULAR}

\section{MICHELLE BORGES}

Engenheiro Agrônomo

Orientador: Dr. OTÁVIO ANTÔNIO DE CAMARGO

Dissertação apresentada à Escola Superior de Agricultura "Luiz de Queiroz", Universidade de São Paulo, para obtenção do título de Mestre em Agronomia, Área de Concentração: Solos e Nutrição de Plantas.

PIR A C I C A B A

Estado de São Paulo - Brasil

Janeiro - 2002 
Dados Internacionais de Catalogação na Publicação (CIP) DIVISÃO DE BIBLIOTECA E DOCUMENTAÇÃO - ESALQ/USP

\section{Borges, Michelle}

Extratabilidade do cádmio : influência de atributos de solos muito intemperizados em extratores convencionais e potencialidade de ácidos orgânicos de baixo peso molecular / Michelle Borges. - - Piracicaba, 2002.

$76 \mathrm{p}$.

Dissertação (mestrado) - - Escola Superior de Agricultura Luiz de Queiroz, 2002.

Bibliografia.

1. Adsorção 2. Cádmio 3. Extratos químico 4. Poluição do solo 5. Toxidade do solo I. Título

CDD 631.41

\section{"Permitida a cópia total ou parcial deste documento, desde que citada a fonte - $O$ autor"}


Aos meus pais, "Mauro" e "Beth"

Ao meu irmão Marcello

Ao meu namorado

Riley

Dedico 


\section{AGRADECIMENTOS}

- À FAPESP pelo auxílio recebido para este projeto e bolsa concedida

- Ao prof. Dr. Otávio Antônio de Camargo, pela orientação e ensinamentos

- À ESALQ e ao IAC por possibilitar a realização desta pesquisa

- Ao Departamento de Solos e Nutrição de Plantas da ESALQ e à Seção de Pedologia e de Fertilidade do Solo e Nutrição de Plantas do Instituto Agronômico de Campinas e seus funcionários

- Às pesquisadoras Dras. Cleide Aparecida de Abreu e Mônica Ferreira de Abreu, do IAC, pelas sugestões e colaboração nos trabalhos

- Ao professor José Carlos Casagrande, da UFSCar campus de Araras, pelos primeiros incentivos científicos

- Ao professor Norberto Lavorenti, da UFSCar campus de Araras, pela ajuda estatística

- Ao professor Luís Reynaldo Ferracciú Alleoni e Dr. Ronaldo Berton pela colaboração

- Ao amigo Marco de Alcântara do IAC que muito me ajudou e ensinou

- Aos amigos Marcio Roberto Soares, Tiago Osório Ferreira e Roberta Cristina Sartini Vieira pela ajuda e paciência

- Às técnicas Renata e Karina, da seção de Pedologia e Fertilidade do IAC, pela colaboração nas determinações, em especial, de Cd

- A todos que de alguma forma contribuíram para a execução deste trabalho

- À toda a minha família, pelo carinho e paciência para que eu pudesse realizar este trabalho

- A Deus por iluminar o meu caminho 


\section{SUMÁRIO}

Página

RESUMO …..................................................................................... viii

SUMMARY ................................................................................... $x$

1 INTRODUÇÃO ...........................................................................

2 REVISÃO DE LITERATURA …....................................................... 4

2.1 Cd no solo e sua disponibilidade para as plantas e animais .......... 5

2.2 Fatores que afetam a adsorção de cádmio ....................................... 7

2.3 Fatores que influenciam na dessorção de cádmio ........................... 9

2.4 Fatores que afetam a liberação do cádmio à solução ..................... 10

3 MATERIAL E MÉTODOS ............................................................... 17

3.1 Solos escolhidos e sua coleta ......................................................... 17

3.2 Caracterização química e física ...................................................... 19

3.3 Análises físicas e químicas das variáveis independentes .............. 20

3.3.1 Análise textural ....................................................................... 20

3.3.2 Análises químicas ................................................................ 20

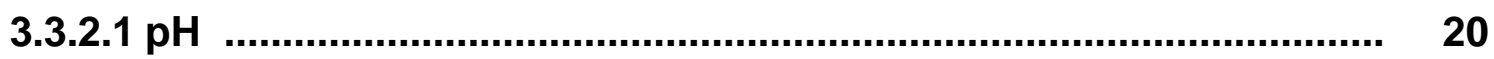

3.3.2.2 Carbono orgânico ................................................................ 20

3.3.2.3 Cátions trocáveis e CTC ........................................................ 21

3.3.2.4 Óxidos de ferro e alumínio cristalinos ...................................... 21

3.3.2.5 Cádmio total ................................................................................ 21

3.4 Extratores de cádmio estudados ................................................. 22

3.4.1 Mehlich 3 .................................................................................... 22 


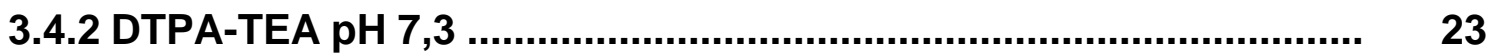

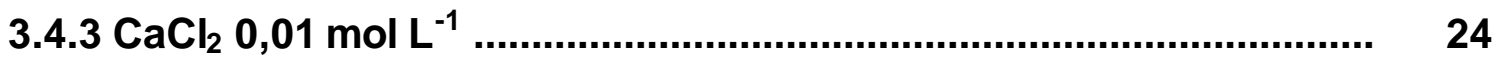

3.4.4 Cálculo do limite de detecção para um ICP-AES ........................... 24

3.4.5 Emprego dos ácidos orgânicos .................................................. 25

3.4.5.1 Ácido acético .......................................................................... 26

3.4.5.2 Ácido cítrico ........................................................................ 26

3.4.5.3 Ácido oxálico .......................................................................

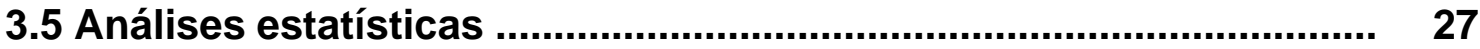

4 RESULTADOS E DISCUSSÃO …....................................................... 28

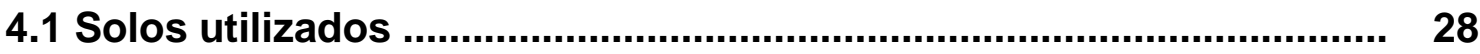

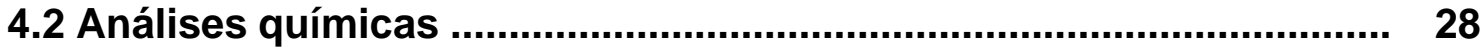

4.2.1 Análises químicas de rotina ..................................................... 28

4.3 Variáveis independentes estudadas .............................................. 32

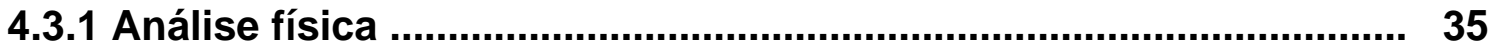

4.3.2 Carbono orgânico …....................................................................... 35

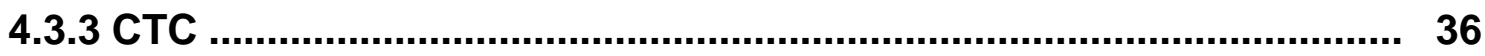

4.3.4 Ferro e alumínio solúveis em ditionito-citrato-bicarbonato ........... 36

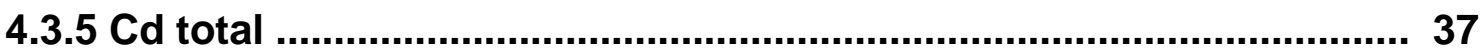

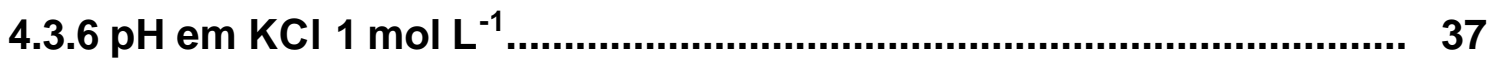

4.4 Influência de atributos do solo na extração do $\mathrm{Cd}$ pelos três extratores convencionais

4.4.1 Análise de correlação simples entre DTPA-TEA pH 7,3, Mehlich 3 e $\mathrm{CaCl}_{2}$ 0,01 $\mathrm{mol} \mathrm{L}^{-1} \mathrm{e}$ atributos do solo

4.4.2 Análises de regressão simples entre os extratores convencionais e as variáveis independentes para os quinze solos estudados

4.4.3 Análise de regressão múltipla entre os extratores convencionais e as variáveis independentes dos solos naturais ....................................44

4.5 Potencialidade de extração de Cd por ácidos orgânicos ................. 45

4.5.1 Na concentração da solução do solo ......................................... 45

4.6 Extração de Cd em solos contaminados .......................................... 47 


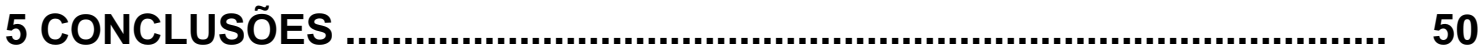

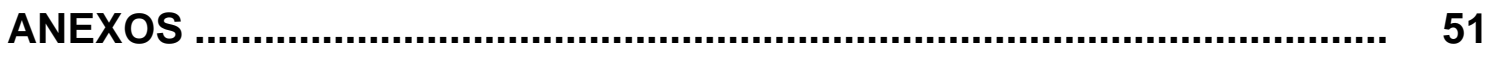

REFERÊNCIAS BIBLIOGRÁFICAS ................................................ 68 


\title{
EXTRATABILIDADE DO CÁDMIO: INFLUÊNCIA DE ATRIBUTOS DE SOLOS MUITO INTEMPERIZADOS EM EXTRATORES CONVENCIONAIS E POTENCIALIDADE DE ÁCIDOS ORGÂNICOS DE BAIXO PESO MOLECULAR
}

\author{
Autora: Michelle Borges \\ Orientador: Dr. Otávio Antônio de Camargo
}

\section{RESUMO}

A determinação de elementos tóxicos em solo é uma importante ferramenta para monitorar a poluição ambiental. O cádmio é um elemento potencialmente tóxico às plantas, aos animais superiores e ao homem, podendo estar presente no ambiente, natural ou antropicamente, em condição de causar toxicidade. Pouco se conhece sobre o comportamento desse cátion nos solos tropicais muito intemperizados, e que apresentam atributos diferentes daqueles de regiões temperadas onde a maioria dos estudos têm sido conduzidos. Esse trabalho teve como objetivos verificar: a) a extratabilidade do cádmio nas amostras de solos naturais com extratores químicos convencionais como o DTPA-TEA pH 7,3, o Mehlich 3 e o $\mathrm{CaCl}_{2} 0,01 \mathrm{~mol} \mathrm{~L}^{-1}$ relacionando-a com os diversos atributos dos solos, b) a potencialidade de extração do Cd pelo uso de soluções de ácidos orgânicos de baixo peso molecular (acético, cítrico e oxálico) que foi comparada com os extratores convencionais e c) a extratabilidade do cádmio em amostras de solos provenientes de regiões 
contaminadas usando-se os mesmos extratores convencionais e orgânicos. As relações solo:solução utilizadas foram para Mehlich 3, DTPA-TEA pH 7,3, $\mathrm{CaCl}_{2} 0,01 \mathrm{~mol} \mathrm{~L}^{-1}$, ácido acético $57 \mathrm{mmol} \mathrm{L}^{-1}$, ácido cítrico $2,1 \mathrm{mmol} \mathrm{L}^{-1} \mathrm{e}$ ácido oxálico 10,4 mmol $\mathrm{L}^{-1}$, respectivamente, as seguintes: 2,5:25; 10:20; 1:10; 10:20; 10:20 e 10:20 ( $\mathrm{g} / \mathrm{ml})$. Foram feitas análises de regressão simples obtendo-se correlação negativa significativa $(r=0,73)$ entre o Cd extraído pelo DTPA-TEA pH 7,3 e o teor de argila dos solos naturais, entre o extrator e o teor de ferro livre $(r=0,65)$ e entre o extrator e o $\mathrm{pH}$ em KCl $1 \mathrm{~mol} \mathrm{~L}^{-1}(r=0,47)$. Análises de regressão múltipla também foram feitas obtendo-se correlação negativa significativa $\left(R^{2}=0,528\right)$ entre o DTPA-TEA pH 7,3 e o teor de argila. $\mathrm{O}$ extrator DTPA-TEA pH 7,3 foi o que apresentou diferença significativa e maior extratabilidade de $\mathrm{Cd}$ em solos naturais. As soluções de $\mathrm{CaCl}_{2} \mathbf{0 , 0 1} \mathrm{mol}$ $\mathrm{L}^{-1}$ e os ácidos orgânicos extraíram pequena quantidade de $\mathrm{Cd}$ dos solos naturais. Para as amostras de solos contaminados a solução de ácido acético foi a que mostrou maior potencialidade de extração do elemento. 


\title{
EXTRATIBILITY OF CADMIUM: INFLUENCE OF VERY WETHEKED SOIL ATTRIBUTES IN CONVENTIONAL EXTRACTANTS AND POTENTIAL OF LOW-MOLECULAR-WEIGHT ORGANIC ACIDS
}

\author{
Author: Michelle Borges \\ Adviser: Dr. Otávio Antônio de Camargo
}

\section{SUMMARY}

The determination of toxic elements in the soil is an important tool for monitoring environmental pollution. Cadmium is an element potentially toxic to the plants, superior animals and man. Not too much is known about of this cation the behaviour in the very weathered tropical soils which present different attributes from the areas where most of the studies has ben conducted. The objectives of this paper was to verify: a) the extractability of cadmium in natural and contaminated soil samples with the addition of chemical extractants DTPATEA pH 7,3, MEHLICH 3 and $\mathrm{CaCl}_{2} 0,01 \mathrm{~mol} \mathrm{~L}^{-1}$ and relate the amount extracted with different soil attributes, b) the extractability potential of three lowmolecular-weight organic acids (acetic, citric and oxalic acids) and compare to the conventional extractants and $c$ ) the extratibility of cadmium in soil samples from polluted areas with the same conventional and organic extractants. The soil:solution ratios used for Mehlich 3, DTPA-TEA pH 7,3, $\mathrm{CaCl}_{2} 0,01 \mathrm{~mol} \mathrm{~L}^{-1}$, acetic acid $57 \mathrm{mmol} \mathrm{L}^{-1}$, citric acid $2,1 \mathrm{mmol} \mathrm{L}^{-1}$ and oxalic acid $10,4 \mathrm{mmol} \mathrm{L}^{-1}$, were respectively, the following: 2,5:25; 10:20; 1:10; 10:20; 10:20 and 10:20 
$(m / v)$. Simple linear regression analysis showed negative correlations $(r=-0,73)$ just for DTPA-TEA pH 7,3 extractable $\mathrm{Cd}$ and soil clay content, and free $\mathrm{Fe}$ content $(r=-0,65)$ and $\mathrm{pH}$ in $\mathrm{KCl}$ solution $(r=-0,47)$. Multiple regression analysis was also performed and a significant negative correlations $\left(R^{2}=0,528\right)$ obtained just for DTPA-TEA pH 7,3 extractable cadmium and soil clay content. The DTPA-TEA pH 7,3 extractant presented the highest results for $\mathrm{Cd}$ extratability in natural soils. The $\mathrm{CaCl}_{2} 0,01 \mathrm{~mol} \mathrm{~L}^{-1}$ and organic acids solutions extracted very low amount of $\mathrm{Cd}$ in natural soils, almost always near the detection limit of the equipament. For contaminated soil samples the acetic acid solution presented the biggest extraction potential for $\mathrm{Cd}$. 


\section{INTRODUÇÃO}

O elevado crescimento populacional e a concentração urbana têm como conseqüência um aumento de produção de resíduos urbano, industrial e agrícola. A disposição inadequada desses resíduos no solo culmina com a poluição da água e do solo com metais pesados, dentre eles o cádmio. O incremento crescente da circulação de metais pesados tóxicos no solo, na água e no ar, e sua inevitável transferência para a cadeia alimentar humana representa um importante problema ambiental com riscos muitas vezes desconhecidos (Nriagu \& Pacyna, 1988). Diante disso, a ciência procura soluções para tais problemas que constituem uma séria ameaça à qualidade de vida.

Uma vez no ambiente, os metais pesados tendem a se acumular, provocando uma elevação constante dos seus níveis. No solo agrícola, os metais geralmente fixam-se na camada de $0-20 \mathrm{~cm}$ de profundidade (Sadovnikova e Zyrin, 1986). Nos seres vivos, tais elementos reagem com ligantes, o que, muitas vezes, Ihes conferem propriedades de bioacumulação e biomagnificação na cadeia alimentar, provocando distúrbios nos processos metabólicos em diferentes espécies da biota (Tavares e Carvalho, 1992). O conhecimento do comportamento desses metais nos resíduos e no sistema solo-planta é de suma importância para que se possam estabelecer formas para seu controle, diminuindo os riscos de poluição ambiental e de acúmulo nos animais superiores e no homem.

Os metais pesados são altamente reativos do ponto de vista químico, o que explica a dificuldade de encontrá-los em estado puro na natureza. Normalmente, apresentam-se em concentração muito pequena, associados a 
outros elementos químicos, formando minerais em rochas. O cádmio pode ser encontrado em resíduos de diversos setores industriais, sendo os mais importantes os de revestimento, tintas e plástico. O elemento pode ser adicionado ao solo por meio de restos de metais fundidos com zinco, resíduos de pneus, óleos combustíveis e lubrificantes, lodo de esgoto, lixo urbano e fertilizantes fosfatados (Raij, 1991).

Diversos estudos estabeleceram que as concentrações médias de $\mathrm{Cd}$ na litosfera, nos solos, sem e com pastagem, e nas plantas foram, respectivamente: 0,$2 ; 0,06 ; 0,01$ e 0,7 , e $0,2-0,8 \mu \mathrm{g} \mathrm{g}^{-1}$ de material seco Haynes \& Greenland, 1981). Para esse elemento a United States Environmental Protection Agency (USEPA) estabelece como padrão de nível crítico de qualidade do solo 20 $\mathrm{mg} \mathrm{kg}^{-1}$. Todavia, pela Diretriz da Comunidade Européia, o nível crítico estabelecido é de 1 a $3 \mathrm{mg} \mathrm{kg}^{-1}$.

O cádmio é facilmente absorvido e translocado pelas plantas em virtude de sua grande capacidade de movimentação. Por ser um cátion, tem sua disponibilidade para as plantas acentuada em meio ácido e, por outro lado, reduzida pela elevação do pH (Raij, 1991).

Alguns pesquisadores estudaram o comportamento do cádmio em camadas superficiais de solos do Brasil (Omae, 1984; Amaral Sobrinho et al., 1992; Matos, 1995 e Pombo, 1995), mas há ainda uma grande lacuna de conhecimento, em especial no que se refere àdessorção, liberação e extração deste elemento em solos muito intemperizados.

O conhecimento dos processos que controlam a disponibilidade e mobilidade de cádmio em solos é importante para a predição de seu transporte no meio ambiente e para o entendimento do seu ciclo biogeoquímico, visando a redução de possíveis efeitos deletérios sobre a qualidade do solo e do ambiente. Os teores de metais pesados da camada arável das amostras de solo permite identificar áreas potencialmente contaminadas refletindo, em parte, as práticas agrícolas empregadas (Abreu et al., 1998). Apesar de não se conhecer a extensão da ocorrência de solos brasileiros contaminados por metais pesados, 
torna-se importante avaliar o grau de contaminação do solo, prever a quantidade de metais presentes nestes solos que será absorvida pelas plantas e, por conseqüência, que entrará na cadeia alimentar.

\section{HIPÓTESE}

Atributos do solo que influenciam a adsorção/dessorção de $\mathrm{Cd}$ devem influenciar a extração do elemento por extratores convencionais.

Ácidos orgânicos de baixo peso molecular são gerados pela quebra de moléculas grandes de resíduos orgânicos ou exsudatos radiculares, aumentando a solubilidade de metais pesados, como o cádmio, por meio de reações de complexação que podem influir na distribuição das diferentes formas químicas do elemento no solo.

\section{OBJETIVO}

Os objetivos do presente trabalho foram estudar a influência de atributos dos solos na extração de $\mathrm{Cd}$ por três extratores convencionais Mehlich 3, DTPA-TEA pH 7,3 e CaCl $20,01 \mathrm{~mol} \mathrm{~L}^{-1}$ e verificar a potencialidade de extração de Cd natural ou não por três ácidos orgânicos de baixo peso molecular (ácido acético, cítrico e oxálico). 


\section{REVISÃO DE LITERATURA}

O crescimento urbano e o conseqüente avanço industrial e tecnológico, levam ao aumento da produção e quantidade de resíduos que lançados no ambiente alteram as condições de equilíbrio da natureza, seja pela violação, ou exaustão dos recursos naturais, seja pela acumulação de rejeitos conduzidos à poluição do solo, do ar, dos recursos hídricos, em detrimento da qualidade de vida em nosso planeta (Castro Neto, 1985). Os processos de descontaminação são muito trabalhosos e, até certo ponto, pouco eficientes. Portanto uma vez contaminado, o solo permanecerá dessa forma por muito tempo.

A Europa recentemente tem transformado suas leis de proteção ambiental tornando-as cada vez mais severas com relação, principalmente, à incineração e à disposição no solo do lodo de esgoto, assim como do lixo urbano e outros resíduos, produzidos pela sociedade (Stentiford, 1992). Segundo Pereira Neto (1992), um modo para equacionar os problemas destes resíduos deve ser uma solução que seja obtida de processos que absorvam ao máximo os diversos tipos de resíduos, pautada nos princípios ecológicos de reaproveitamento de energia e proteção dos recursos naturais sendo uma solução de tratamento, compatível com o desenvolvimento econômico e social do País, exercendo cidadania e preservando o ambiente.

Conceitos como poluição e contaminação devem ser esclarecidos. Segundo Holdgate (1979), citado por Alloway (1990), poluição é a introdução, pelo homem, no ambiente, de substâncias ou energias capazes de causar problemas à saúde humana, prejuízos aos recursos biológicos e aos sistemas ecológicos, bem como ocasionar interferência no uso adequado do meio ambiente. O termo contaminação é mais usado para situações em que as 
modificações oriundas da intervenção do homem parecem não causar efeitos prejudiciais evidentes. Embora na literatura os conceitos sejam diferentes, juridicamente não há diferença.

Dentre as atividades que podem poluir os solos agrícolas, citam-se os corretivos da acidez, resíduos da indústria siderúrgica, lixo urbano, lodo de esgoto e aplicação de alguns fertilizantes fosfatados em solos agrícolas.

\subsection{Cd no solo e sua disponibilidade para as plantas e animais}

O termo metais pesados se dá para elementos (metais) que apresentam densidade superior a $6,0 \mathrm{~kg} \mathrm{dm}^{-3}$. Outro termo normalmente utilizado é a denominação metais tóxicos que se aplica para elementos não essenciais, tais como Pb, Cd, Hg, As, Ti e U (Alloway, 1990).

Os fatores que afetam a distribuição química dos metais pesados no solo evidentemente controlam sua solubilidade e mobilidade no ambiente, influindo diretamente na disponibilidade desses às plantas e animais. Consideram-se prontamente disponíveis para plantas e outros organismos os metais em formas solúveis, dissolvidos na solução do solo, ou na forma trocável, adsorvido às cargas do solo. Os metais precipitados, ocluídos e formando quelatos pouco solúveis com a matéria orgânica não estão disponíveis, mas podem passar para a solução do solo pela mineralização dos ligantes orgânicos ou mudanças drásticas de pH ou potencial redox (Pickering, 1981; Emmerich, et al., 1982; Coker e Mattews, 1983; Alloway, 1990).

Segundo Lindsay (1979) além do pH, a adsorção e a atividade de microrganismos são fatores importantes no controle do nível de micronutrientes no solo. Considerando ainda a fase mineral como o agente controlador fundamental da quantidade dos elementos na solução. Assim, em meio alcalino, muitos metais pesados tornam-se menos solúveis formando precipitados, como hidróxidos e carbonatos, e, consequentemente, são menos disponíveis para as 
plantas. Com a elevação do pH tem-se também o aumento da CTC do solo, incrementando a adsorção de cátions. Esse efeito pode ser mais pronunciado em solos com carga variável, tais como oxissolos intemperizados contendo gibbsita e goethita (Hue et al., 1988).

As reações que controlam a disponibilidade dos elementos em solos compreendem os processos de adsorção/dessorção, precipitação/dissolução e complexação (Barrow, 1989).

Assim como o pH, a força iônica, o tempo de contato e também a presença de ligantes orgânicos e inorgânicos, previamente adsorvidos (Guilherme \& Anderson, 1997) ou em solução (Guilherme et al., 1995; Ali \& Dzombak, 1996), afetam a disponibilidade de metais pesados no solo. Uma concentração excessiva de ligantes em solução tende a diminuir a adsorção de metais pesados nos componentes do solo por efeito de competição ou complexação (McBride, 1994; Ali \& Dzombak, 1996), enquanto que uma paridade molar ligante:metal favorece a adsorção do metal (Guilherme et al., 1995) possivelmente pela formação de complexos ternários do tipo solo-ligante-metal (McBride, 1994).

Segundo Alloway (1990), a absorção de metais pelas plantas é dependente dos fatores que controlam os processos de especiação e as concentrações do metal na solução do solo, o movimento do metal do solo para a superfície da raiz, o transporte do metal da superfície radicular para dentro das raízes e a translocação do metal das raízes para a parte aérea da planta. Com respeito à especiação de sólidos, muitos trabalhos têm sido realizados em relação à extração química e absorção de metais pela planta. Nesse sentido, dependência altamente significativa tem sido encontrada entre absorção de metais pelas plantas e metais extraídos com soluções de DTPA-TEA pH 7,3, EDTA, $\mathrm{HOAc}, \mathrm{NH}_{4} \mathrm{Oac}$ e $\mathrm{KNO}_{3}$. Deve ser mencionado, entretanto, que os metais retirados por esses extratores, na maioria das vezes, não estão relacionados com o disponível ao vegetal, já que pouco se conhece a respeito das características biofísico-químicas da rizosfera. 
O efeito que tem sido mais observado com relação à absorção de metais pesados pelas plantas é a redução da produção de biomassa e da qualidade nutricional (Van Assche et al., 1988). A acumulação desses elementos depende da espécie e do nível do metal encontrado no solo (Bingham et al., 1975). A habilidade das plantas em absorver metais pesados varia muito. De modo geral, a seqüência decrescente do índice de bioacumulação para diferentes plantas é: $\mathrm{Cd}>\mathrm{Zn}>\mathrm{Cu}>\mathrm{Pb}>\mathrm{Ni}$ (Kabata-Pendias e Pendias, 1984).

Segundo a legislação brasileira (ASSOCIAÇÃO BRASILEIRA DAS INDÚSTRIAS DA ALIMENTAÇÃO, 1985), os limites máximos permitidos em alimentos são: 1,0; 5,0; 8,0; 30 e $50 \mathrm{mg} \mathrm{kg}^{-1}$ de matéria seca para $\mathrm{Cd}, \mathrm{Ni}, \mathrm{Pb}$, Cu e $\mathrm{Zn}$, respectivamente.

\subsection{Fatores que afetam a adsorção de cádmio}

Os metais pesados presentes em baixas concentrações tendem a ser retidos no solo via adsorção, principalmente na forma não trocável (McBride, 1989).

A adsorção específica mostra evidências indiretas da formação de complexos de esfera interna entre a superfície dos óxidos e metais pesados, entre elas citam-se: a grande especificidade dos óxidos por certos metais pesados e a mudança na carga líquida de superfície em virtude da adsorção do metal (McBride, 1989). A contribuição da adsorção específica para a retenção de metais pesados em solos pode ser avaliada pela variação da força iônica da solução, uma vez que metais adsorvidos especificamente são pouco influenciados pelo aumento da força iônica (Barrow, 1989).

Gadde \& Laitinen (1974) mostraram adsorção específica de $\mathrm{Pb}^{2+}, \mathrm{Zn}^{2+}$ e $\mathrm{Cd}^{2+}$ em óxido de manganês e $\mathrm{Pb}^{2+}$ e $\mathrm{Cd}^{2+}$ em óxido férrico, seguindo a ordem de adsorção: $\mathrm{Pb}^{2+}>\mathrm{Zn}^{2+}=\mathrm{Cd}^{2+}$. 
Estudos verificaram que o $\mathrm{pH}$, matéria orgânica (M.O.), CTC, superfície específica e força iônica são atributos do solo que melhor se correlacionam com a retenção do cádmio. Maior adsorção é obtida com o aumento do pH (Garcia \& Miragaya, 1978; King, 1988), da matéria orgânica e consequentemente da CTC (Singh, 1979; Petruzzelli et al., 1985), além da superfície específica (Kort et al., 1976). O contrário ocorre com a elevação da força iônica (Garcia-Miragaya \& Page, 1976; Petruzzelli et al., 1985; Matos, 1995). Singh (1979) também mostrou que a maior porção de cádmio adsorvido e de cádmio não liberado (fixado), estava correlacionada à $\mathrm{CTC}, \mathrm{pH}$ e teores de carbono orgânico contidos nos solos estudados, e que as reações de fixação do cádmio não tiveram prioridade nas reações de adsorção do elemento. Dias (1999) mostrou que a CTC foi o atributo que teve o maior efeito sobre a adsorção de Cd para um Nitossolo Vermelho eutroférrico e dois Latossolos do estado de São Paulo. De certa forma existe uma contradição entre estes resultados e os de Gadde \& Laitinen (1974) e de McBride (1989) na medida que se espera que o Cd retido por ligações de troca não o seja por adsorção específica. Estas correlações podem ser circunstanciais apenas, pois pode acontecer que onde a CTC aumenta, aumenta porque o teor de argila e M.O. elevam que por sua vez estão relacionados com os teores de óxidos de Fe, Al e Mn.

Garcia-Miragaya \& Page (1976) notaram que a adsorção de $\mathrm{Cd}^{2+}$ em solução de cloreto é fortemente afetada pela força iônica, isto pelo fato de o coeficiente de atividade do $\mathrm{Cd}^{2+}$ ser baixo em altas concentrações de sais, como também por formar espécies como $\mathrm{CdCl}^{+}$e $\mathrm{CdCl}_{2}{ }^{0}$, além de outras. As espécies de cádmio ligadas ao cloreto não são adsorvidas tão fortemente aos colóides do solo quanto o $\mathrm{Cd}^{2+}$.

Barrow et al. (1989) verificaram que o pH altera a adsorção de cádmio em virtude do seu efeito sobre o potencial elétrico. Assim, na adsorção de Cd por goetita o efeito do $\mathrm{pH}$ deveu-se à dissociação do íon metálico em solução e do efeito sobre o potencial elétrico de superfície. $\mathrm{O}$ íon $\mathrm{Cd}^{2+}$ em solução tende a sofrer hidrólise, resultando em $\mathrm{CdOH}^{+}$. O valor de $\mathrm{pK}$ apresentado por esta 
dissociação é de 10,08, valor bem maior que a faixa de $\mathrm{pH}$ existente para a maioria dos solos do Brasil. Assim, a adsorção aumenta com a elevação do pH aproximando-se desse valor.

\subsection{Fatores que influenciam na dessorção de cádmio}

A disponibilidade de cádmio nos solos para as plantas depende da sua dessorção da superfície dos materiais coloidais do solo para a solução. Apesar de os estudos de adsorção de nutrientes e do cádmio serem relativamente numerosos, poucos têm examinado o processo da dessorção (Hogg et al., 1993). Isto é paradoxal porque em situações de deficiência de nutrientes é o processo de dessorção que controla a quantidade e a taxa da liberação dos elementos para a planta (Bolt et al., 1986).

Hogg et al. (1993) verificaram que a dessorção depende não somente do total de cádmio lábil do solo, como também do $\mathrm{pH}$ do solo, temperatura, quantidade do elemento adicionado e do tempo de contato solo:solução.

Assume-se nos estudos de reversibilidade de troca, que a forma de troca catiônica é idêntica na adsorção e na dessorção de um íon. Sabe-se entretanto, que o processo de dessorção pode ser afetado pela histerese (Evangelou, 1998). Trabalhos mostraram que os metais ligados à matéria orgânica são rapidamente adsorvidos, enquanto a dessorção ocorre de modo mais lento. Assim, a liberação tende a ser lenta e/ou incompleta (em razão da histerese), pois os complexos de esfera interna requerem energia de ativação grande para o processo de dessorção (McBride, 1989). O surgimento do efeito da histerese é afetado pelo período de equilíbrio (Evangelou, 1998). Assim, ela tende a ser tanto menor (maior histerese) quanto maior for o tempo de contato do solo com o elemento (Barrow, 1985; Padmanabham, 1983). 
No que diz respeito a planta e nutrição animal, o conhecimento do processo de dessorção e os fatores por ele controlados é tão importante quanto, ou mais importante, que o entendimento do processo de adsorção (Bolt et al., 1986).

\subsection{Fatores que afetam a liberação do cádmio à solução}

A absorção de nutrientes dos solos pelas plantas, por meio das raízes, é geralmente enfatizado sendo diretamente via iônica ou por sistemas de transporte ativo. Até o presente, os mecanismos de absorção de metais contaminantes, e igualmente de alguns micronutrientes, pelas raízes das plantas são pouco conhecidos. É realmente improvável que as plantas tenham desenvolvido mecanismos de absorção específica para metais não essenciais. Provavelmente, os contaminantes são transportados através das membranas como substitutos de nutrientes de mesmo mecanismo de transporte, ou interrupção na barreira endodermal junto aos sítios de iniciação das raízes laterais ou nos ápices das raízes (McLaughlin et al., 1999).

A disponibilidade do $\mathrm{Cd}$ depende das propriedades do solo pelo fato de o metal associado à fase sólida estar presente numa ampla variedade de formas químicas. Segundo Sposito (1989) a maior parte das espécies de Cd na solução do solo são $\mathrm{Cd}^{2+}, \mathrm{CdCl}^{+}, \mathrm{CdHCO}_{3}{ }^{+}$e $\mathrm{CdSO}_{4}{ }^{0}$. Em adição, o Cd é preferencialmente móvel nos solos, e a forma desse metal absorvida pelas plantas é a do íon livre, $\mathrm{Cd}^{2+}$, mas, formas queladas como $\mathrm{CdCl}^{+}$também podem ser absorvidas pelas plantas (Wolt, 1994).

Durante as duas últimas décadas consideráveis esforços têm sido dedicados para o desenvolvimento de soluções extratoras adequadas para avaliar o estado nutricional dos solos. Componentes inorgânicos bem como orgânicos têm sido propostos como constituintes de soluções extratoras para diferentes elementos. A complexa natureza dos processos do solo e das relações solo-planta é provavelmente uma das maiores razões para a 
existência de um grande número de métodos para avaliar a fração de nutrientes e metais pesados disponível na planta (Krishnamurti et al., 2000).

Muitos extratores vêm sendo recomendados para o uso como índices de fitodisponibilidade. A maioria dos métodos são baseados no estabelecimento de uma significativa correlação entre quantidades de metais pesados extraídos e de metais contidos nas plantas (Krishnamurti et al., 2000). Muitos são os métodos de extração existentes, entretanto para a seleção de um determinado método necessita-se de estudos regionais para se avaliar qual o método que melhor se adapta às condições dos solos e que se correlacione com a resposta das plantas. A maioria das análises de solo para a avaliação da disponibilidade de nutrientes, consiste em agitar uma amostra de solo com uma solução extratora por um determinado período de tempo. A solução extratora deve ser capaz de extrair quantidades proporcionais às formas disponíveis de um nutriente no solo, e a quantidade extraída deve ser mensurável e também se correlacionar com o crescimento de cada cultura (Abreu, 1997).

Várias técnicas de extração vêm sendo desenvolvidas ao longo dos anos, para várias combinações de metais, tipos de solos, espécies de plantas e ambientes, que muitas vezes são limitadas mas de proveitosas aplicações. Com avanços recentes na instrumentação analítica, extrações mais sofisticadas de solos e técnicas de determinações de elementos têm sido possíveis. Isto, combinado com um melhor entendimento do comportamento dos metais no solo, está conduzindo a uma rápida melhora nas técnicas de diagnóstico para avaliar os riscos dos metais pesados nos solos (McLaughlin et al., 1999).

Diversos extratores químicos têm sido usados para a avaliação da fitodisponibilidade dos metais pesados. A escolha, normalmente, se dá em função das quantidades extraídas e crescimento de plantas ou quantidades adsorvidas. Os numerosos extratores usados podem ser agrupados em vários tipos de acordo com suas propriedades e modo de ação. Geralmente, os extratores químicos podem ser agrupados em extratores salinos $\left(\mathrm{CaCl}_{2}\right.$, $\left.\mathrm{NaNO}_{3}, \mathrm{Ca}\left(\mathrm{NO}_{3}\right)_{2}\right)$, extratores ácidos $\left(\mathrm{HCl} \mathrm{0,1} \mathrm{mol} \mathrm{L} \mathrm{L}^{-1}, \mathrm{HNO}_{3} 0,1 \mathrm{~mol} \mathrm{~L}^{-1}\right.$, 
Mehlich 1, Mehlich 3) e ligantes orgânicos (EDTA e DTPA). Os extratores salinos têm a capacidade de extrair formas que ocorrem na solução do solo e formas fracamente adsorvidas, enquanto os extratores ácidos extraem teores próximos ao total. Os ligantes orgânicos, por sua vez extraem metais que estão associados a formas orgânicas e carbonatos (Hao et al., 1980; Sposito et al., 1982; Hani \& Gupta, 1985; Kiekens \& Cottenie, 1985; Gunn et al., 1988; Levy et al., 1992; McGrath \& Cegarra, 1992; Haddad \& Evans, 1993).

Até recentemente, os extratores salinos eram pouco utilizados em análises de metais em solos por causa da sua baixa capacidade de extração, dificultando a determinação dos metais por técnicas instrumentais comuns. Hoje, com o uso de novas técnicas o uso dessas soluções tornou-se mais rotineiro. Diversas soluções salinas são utilizadas para extração de metais. Essas soluções extraem preferencialmente os metais dos sítios de troca iônica de metais, no entanto, as suas concentrações e as relações solo:solução são as mais diversas o que torna difícil a comparação entre elas (Abreu et al., 2002). O $\mathrm{CaCl}_{2}$ pertence ao grupo de soluções de sal neutro, e é tido como o melhor extrator para avaliação da disponibilidade de metais pesados, sendo um método rápido e simples para avaliar a fitodisponibilidade das plantas. Contudo, em alguns casos, as soluções de sais fracassam e as causas disto não estão explicadas satisfatoriamente. Dados relatados em diferentes estudos revelam a falha da estimativa no modo de extração dos metais por essas soluções de sais. Muitas vezes extratores de solo são usados não levando em consideração o modo de ação e a química dos metais pesados. $\mathrm{O} \mathrm{CaCl}_{2}$ sempre é um extrator moderado quando comparado com o DTPA-TEA pH 7,3, e nos solos 0 $\mathrm{CaCl}_{2}$ sempre extrai quantidades pequenas de metais (Hooda, 1997). A extração por DTPA-TEA pH 7,3 é baseada na habilidade de formar complexos estáveis com muitos metais pesados. O extrator DTPA-TEA pH 7,3 solubiliza competindo com sucesso com a matéria orgânica. No caso do $\mathrm{CaCl}_{2}$ a extração é principalmente baseada no deslocamento de metais trocáveis pelo $\mathrm{Ca}^{2+}$. 
O DTPA-TEA pH 7,3 é tido também como um extrator quelante apresentando como característica a combinação com o íon metálico em solução formando complexos solúveis, reduzindo sua atividade em solução. Com isso, os íons dessorvem da superfície do solo ou dissolvem da fase sólida reestabelecendo o equilíbrio da solução. Este extrator foi proposto por Lindsay \& Norvell (1978) consistindo de DTPA $0,005 \mathrm{~mol} \mathrm{~L}^{-1}$ (ácido dietilenotriaminopentacético), trietanolamina $0,1 \mathrm{~mol} \mathrm{~L}^{-1}$ e CaCl $20,01 \mathrm{~mol} \mathrm{~L}^{-1}$. A adição de $\mathrm{CaCl}_{2} 0,01 \mathrm{~mol} \mathrm{~L}^{-1}$ e de trietanolamina $0,1 \mathrm{~mol} \mathrm{~L}^{-1}$ foi proposta por esses autores para manter a concentração de $\mathrm{Ca}^{2+}$ próxima à encontrada em solos neutros e alcalinos, e o pH relativamente constante. Essas condições foram criadas com o objetivo de retardar a dissolução de $\mathrm{CaCO}_{3}$ em solos calcários e de obter um filtrado límpido pela floculação das partículas coloidais do solo. O método foi originalmente desenvolvido para solos calcários do sudoeste dos Estados Unidos e para identificar solos deficientes em $\mathrm{Cu}, \mathrm{Fe}, \mathrm{Mn}$ e Zn. Seu uso foi ampliado, com relativo sucesso, para solos com má drenagem e, ou, contaminados com metais, condições essas bem diferentes daquelas preconizadas para o método. $O$ agente complexante DTPA-TEA pH 7,3 tem sido extensamente usado para predizer o conteúdo de metais pesados nas plantas baseado nas concentrações dos metais nos extratos do solo e tem muitas vezes apresentado sucesso. Uma série de usos incorretos têm sido identificados, o que provavelmente leva a falha no teste. O extrator está baseado na quelação tendendo a extrair significantes quantidades de elementos traços, e deste modo não reflete necessariamente o conteúdo disponível para as plantas em solos. Para compensar o alto $\mathrm{pH}$ do extrator, é sugerido a inclusão do $\mathrm{pH}$ como uma das variáveis nos estudos de correlação.

$\mathrm{O}$ extrator Mehlich 3 consiste de $\left(\mathrm{CH}_{3} \mathrm{COOH} 0,2 \mathrm{~mol} \mathrm{~L}^{-1}, \mathrm{NH}_{4} \mathrm{NO}_{3} \quad 0,25 \mathrm{~mol}\right.$ $\mathrm{L}^{-1}, \mathrm{NH}_{4} \mathrm{~F} 0,015 \mathrm{~mol} \mathrm{~L}^{-1}, \mathrm{HNO}_{3}$ 0,013 $\mathrm{mol} \mathrm{L}^{-1}$, EDTA 0,001 $\mathrm{mol} \mathrm{L}^{-1} \mathrm{pH} \mathrm{2,5 \pm 0,1)}$ e resultou de modificações no extrator Mehlich 2 com o objetivo de incluir o $\mathrm{Cu}$ nas determinações. A adição do agente complexante EDTA aumentou a extração de $\mathrm{Cu}, \mathrm{Mn}$ e $\mathrm{Zn}$. A adição de $\mathrm{NH}_{4} \mathrm{~F}$ se deu por promover uma 
extratabilidade seletiva de $\mathrm{P}$ mas, mantendo-se $\circ \mathrm{pH}$ em 2,5 $\pm 0,1$ durante 0 processo de extração para uma máxima vantagem do componente fluorídrico. O ácido acético foi introduzido devido sua alta ação de poder tampão.

Em estudos feitos por King \& Hajjar (1990) utilizando os extratores DTPATEA pH 7,3 e Mehlich-3 para conhecer, em condições de casa-de-vegetação, o efeito residual do lodo de esgoto sobre a concentração de metais pesados em plantas de tabaco e amendoim, e usando um podzólico de textura média com três diferentes níveis de $\mathrm{pH}(5,2 ; 5,8$ e 6,4$)$ os melhores resultados foram obtidos para $\mathrm{Cd}, \mathrm{Cu}, \mathrm{Ni}$ e $\mathrm{Zn}$, extraídos do solo com DTPA-TEA pH 7,3. Resultados parecidos foram obtidos por Mulchi et al. (1991) estudando correlações entre os teores de $\mathrm{Cd}, \mathrm{Cu}, \mathrm{Fe}, \mathrm{Mn}, \mathrm{Ni}, \mathrm{Pb}$ e $\mathrm{Zn}$ extraídos por DTPATEA pH 7,3 e Mehlich 1 e 3 de um solo onde havia sido adicionado lodo de esgoto, e os absorvidos por plantas de tabaco. Para extração com DTPA-TEA $\mathrm{pH} \mathrm{7,3} \mathrm{as} \mathrm{melhores} \mathrm{correlações} \mathrm{foram} \mathrm{observadas} \mathrm{para} \mathrm{o} \mathrm{Cd}$, Cu, Ni e Zn.

Segundo Kelling et al. (1977) o DTPA-TEA pH 7,3 pode ser utilizado para prever concentrações de $\mathrm{Cd}$, $\mathrm{Cu}, \mathrm{Ni}$ e $\mathrm{Zn}$ em plantas de centeio, sorgo e milho. Já para Baxter et al. (1983) metais extraídos do solo com DTPA-TEA pH 7,3 não se correlacionam bem com os valores de concentração nas plantas. Nesta mesma linha Hooda (1997) comenta que o $\mathrm{CaCl}_{2}$ é o extrator que representa melhor a realidade da disponibilidade para as plantas dos metais em solo, embora este extrator tenha a desvantagem de extrair metais em uma concentração muito pequena o que dificultaria a determinação analítica.

Apesar do método Mehlich 3 ser uma mistura de ácidos, sais e quelante ele aqui encontra-se incluído entre os extratores ácidos tendo sido desenvolvido para avaliar a disponibilidade de $\mathrm{K}, \mathrm{Mg}, \mathrm{Ca}, \mathrm{Mn}, \mathrm{Fe}, \mathrm{Cu}, \mathrm{Zn}, \mathrm{B}$ e P de solos ácidos do sudoeste dos Estados Unidos (Mehlich, 1984). Este extrator consiste de $\mathrm{CH}_{3} \mathrm{COOH} 0,2 \mathrm{~mol} \mathrm{~L}^{-1}, \mathrm{NH}_{4} \mathrm{NO}_{3} 0,25 \mathrm{~mol} \mathrm{~L}^{-1}, \mathrm{NH}_{4} \mathrm{~F} 0,015 \mathrm{~mol} \mathrm{~L}^{-1}, \mathrm{HNO}_{3}$ $0,013 \mathrm{~mol} \mathrm{~L}^{-1}$ e EDTA $0,001 \mathrm{~mol} \mathrm{~L}^{-1}$ e o $\mathrm{pH}$ ajustado a $2,5 \pm 0,1$. O uso do fluoreto de amônio na solução Mehlich 3 melhorou a predição da disponibilidade de $P$ em solos neutros e alcalinos. $O$ agente quelante DTPA causou 
interferência na determinação colorimétrica do $\mathrm{P}$ e foi substituído pelo EDTA para complexar $\mathrm{Cu}, \mathrm{Fe}, \mathrm{Mn}$ e $\mathrm{Zn}$. Atualmente, esse método tem sido muito empregado para avaliar a disponibilidade de Pb e Cd (Xiu et al., 1991) além de outros metais.

Os extratores químicos (ácido clorídrico, Mehlich 1, Mehlich 3, DTPA, EDTA e água) usados na avaliação da disponibilidade de $\mathrm{Cd}$ em diversos solos para diferentes plantas apresentam diferentes graus de eficiência. Em alguns casos os valores do coeficiente de correlação entre Cd-planta e Cd-solo são altos, em outras situações baixos e, às vezes, não significativos impossibilitando a recomendação de um determinado método para diferentes situações (Abreu et al., 2002).

O entendimento da biologia e química da rizosfera é essencial para determinar a mobilidade e disponibilidade dos metais da interface solo-raiz das plantas. A exsudação de compostos orgânicos pelas raízes pode influenciar a solubilidade dos íons levando a efeitos indiretos na atividade microbiana, propriedades físicas da rizosfera e dinâmica das raízes bem como diretamente na acidificação, quelação, reações de precipitação e oxidação na rizosfera.

Os tipos de solos afetam significativamente a quantidade total dos ácidos orgânicos de baixo peso molecular encontrados na rizosfera, indicando que as propriedades químicas e biológicas dos solos podem alterar a composição e quantidade de ácidos orgânicos presentes (Cieslinski et al., 1998).

O baixo peso molecular dos ácidos orgânicos (acético, cítrico, oxálico e fumárico) secretados pelas raízes das plantas modificam a mobilidade do cádmio, influenciando na formação de complexos solúveis na rizosfera das plantas (Krishnamurti et al., 1997). Além disso, esses compostos orgânicos constituem a principal fonte de energia para os microrganismos que habitam a rizosfera. Uma das principais críticas feitas aos extratores químicos é que estes não simulam as reações que ocorrem nessa região. Segundo Godo \& Reisenauer (1980) e Merckx et al. (1986) como a concentração de metais na 
solução do solo é muito baixa, a sua solubilização quando presentes na fase sólida por exsudatos de raízes na região da rizosfera não deve ser desprezada.

Mench \& Martin (1991) observaram que as quantidades de Cd extraídas pelos exsudatos de raízes coletados de três espécies vegetais (Nicotiana tabacum L., Nicotiana rústica L. e Zea mays L.) foram similares às quantidades absorvidas desse elemento por essas três plantas, quando cultivadas no solo. Parker et al. (1995) demonstraram que a absorção de nutrientes pela planta e a toxicidade de muitos metais mostram grande influência da especiação aquosa do metal, e que as respostas correlacionam-se melhor com a atividade do metal livre em solução. Isto deve-se ao fato de apenas o metal livre, na forma $\mathrm{Cd}^{2+}$, atravessar o plasmalema e entrar no citoplasma da célula. Íons metálicos quelados com ligantes orgânicos ou complexados com ligantes inorgânicos na solução do solo não podem ser absorvidos diretamente.

Krishnamurti et al. (1997) verificaram a influência da liberação de exsudatos orgânicos pelas raízes das plantas na solubilidade dos nutrientes, nos efeitos na atividade microbiana, na propriedade física da rizosfera, no crescimento radicular, na direção de acidificação, na precipitação, nas reações de oxirredução e na formação de quelatos. As biomoléculas no metabolismo de microrganismos têm efeito similar na transformação dos metais. Este fato tem levado pesquisadores a investigar esses exsudatos no sentido de chegar a uma formulação, tal que se possa usar uma espécie de coquetel de espécies orgânicas para uso como extrator de metais. Porém, pouco se conhece sobre a dinâmica da liberação do cádmio nos solos pelos ácidos orgânicos, e não é conhecida qualquer tentativa neste sentido nas condições brasileiras. Assim, o conhecimento da liberação do $\mathrm{Cd}$ dos solos por ácidos excretados pelos exsudatos das raízes é de suma importância no estudo da disponibilidade do elemento no solo. 


\section{MATERIAL E MÉTODOS}

O presente trabalho foi conduzido nos laboratórios do Centro de Solos e Recursos Agroambientais, do Instituto Agronômico de Campinas em Campinas, SP.

\subsection{Solos escolhidos e sua coleta}

A extração do Cd tanto para o estudo da relação entre o teor extraído por três extratores convencionais com os diferentes atributos dos solos como para o teste de extração de três ácidos orgânicos com baixo peso molecular foi estudada em quinze amostras superficiais $(0-20 \mathrm{~cm})$ de solos supostamente não contaminados que foram chamados neste trabalho de naturais. Para a segunda parte do trabalho, que se refere à extração de $\mathrm{Cd}$ e a relação entre os extratores foram usadas amostras supostamente contaminadas de diferentes regiões e que sofreram diferentes tratamentos com contaminação antrópica e que foram cedidas por diversos pesquisadores.

Escolheram-se quinze amostras de solos que além de grande ocorrência e importância econômica no Estado de São Paulo, apresentavam uma amplitude de atributos químicos e físicos adequada para o estudo de sua influência no comportamento do $\mathrm{Cd}$ em relação à extração por diferentes extratores. As amostras desses solos foram secas ao ar, peneiradas, homogeneizadas, acondicionadas e numeradas. A classificação foi realizada segundo o Sistema Brasileiro de Classificação de Solos proposto pela Embrapa (1999) e são acompanhados das legendas, que por facilidade, irão ser usadas ao longo do 
trabalho. As três últimas amostras embora não sejam de solos muito intemperizados foram introduzidas para servir como termo de comparação. São eles:

1. LATOSSOLO VERMELHO Perférrico (LVj);

2. LATOSSOLO VERMELHO Eutroférrico (LVef);

3. LATOSSOLO AMARELO Ácrico (LAw);

4. ARGISSOLO VERMELHO AMARELO Eutrófico (PVAe);

5. ARGISSOLO VERMELHO AMARELO Distrófico (PVAd-1);

6. ARGISSOLO VERMELHO AMARELO Distrófico (PVAd -2);

7. LATOSSOLO VERMELHO Distrófico (LVd);

8. LATOSSOLO VERMELHO Distroférrico (LVdf -1);

9. LATOSSOLO VERMELHO Distroférrico (LVdf -2);

10. LATOSSOLO VERMELHO AMARELO Distrófico (LVAd-1);

11. LATOSSOLO VERMELHO AMARELO Distrófico (LVAd-2);

12. LATOSSOLO VERMELHO AMARELO Ácrico (LVAw);

13. NITOSSOLO VERMELHO Eutroférrico (NVef);

14. NEOSSOLO QUARTZARÊNICO Órtico (RQo);

15. PLANOSSOLO HÁPLICO Distrófico (SXd)

Amostras de solos onde foram incorporados resíduos de fontes distintas, e que sabidamente, apresentam altos teores de $\mathrm{Cd}$ foram selecionadas buscando atingir uma ampla faixa de valores de Cd para serem utilizadas no estudo de sua extração. Estas amostras foram cedidas por diversos pesquisadores e empresas. As amostras são as seguintes:

- Amostras (AM1 a AM3): provenientes de um solo sem identificação, de área contaminada pela indústria Zincomatic, no município de Guararema, SP, no Vale do rio Paraíba, correspondendo respectivamente a uma amostra coletada de uma área onde foi realizado o $2^{\circ}$ furo na franja capilar, uma 
amostra retirada de uma área de várzea e uma amostra retirada de uma área jusante da caixa de sedimentação;

- Amostra (AM4): corresponde a um LATOSSOLO VERMELHO Distrófico com aplicação de lodo de esgoto no período de 1983 a 1987, com ensaio de milho, no município de Limeira, SP;

- Amostras (AM5 e AM6): solo não identificado do município de Caçapava, $\mathrm{SP}$, com fortes indícios de contaminação de indústrias da região sendo as amostras retiradas respectivamente a $0-5 \mathrm{~cm}$ e $5-10 \mathrm{~cm}$ de profundidade;

- Amostras (AM7 e AM8): amostras da região de Alferes, RJ, com indícios de se tratar de uma área possivelmente contaminada por resíduo industrial, retiradas respectivamente a $0-10 \mathrm{~cm}$ e $10-20 \mathrm{~cm}$ de profundidade;

As amostras foram secas ao ar, peneiradas em peneira de $1 \mathrm{~mm}$, homogeneizadas e acondicionadas em frascos de polipropileno.

\subsection{Caracterização química e física}

A caracterização química e física dos solos naturais e contaminados, foi feita seguindo a metodologia preconizada por Camargo et al. (1986), sendo nos solos naturais, analisados atributos como: capacidade de troca de cátions (CTC a pH 7,0) pela soma de bases mais $\mathrm{H}+\mathrm{Al}$; carbono orgânico; $\mathrm{pH}$ em água e em $\mathrm{KCl} 1 \mathrm{~mol} \mathrm{~L}^{-1}$; teor de óxidos de ferro e alumínio livres extraídos com ditionito, complexado com citrato em meio tamponado com bicarbonato; Cd total e o teor de argila. 


\subsection{Análises físicas e químicas das variáveis independentes}

\subsubsection{Análise textural}

O teor de argila, silte e areia, das amostras de solo, foram determinados pelo método da pipeta completando-se o volume de uma proveta de $500 \mathrm{ml}$, agitando a suspensão, anotando o tempo necessário para a sedimentação das diferentes partículas do solo e pesando-se as alíquotas que foram secas em estufa.

\subsubsection{Análises químicas}

\subsubsection{1 pH}

Determinou-se o pH da suspensão de solo, na relação solo:solução 1:2,5 $(\mathrm{m} / \mathrm{v})$, em água e em $\mathrm{KCl} 1 \mathrm{~mol} \mathrm{~L}^{-1}$, com pHmetro equipado com eletrodo combinado de vidro e calomelano. $\mathrm{O} \mathrm{pH}$ aqui adotado foi o utilizado para fins de classificação de solos porque é um parâmetro largamente usado em análises pedológicas e dimunui sensivelmente o efeito salino e melhora a influência do potencial de junção, além de ter relação muito estreita com a presença de alumínio trocável.

\subsubsection{Carbono orgânico}

O carbono orgânico das amostras de solo foi obtido pela oxidação da matéria orgânica do solo com solução de dicromato de potássio em presença de ácido sulfúrico, e titulação do excesso de dicromato com sulfato ferroso amoniacal. 


\subsubsection{Cátions trocáveis e CTC}

Os cátions $\mathrm{Ca}, \mathrm{Mg}, \mathrm{K}$ e Na foram obtidos pela extração com solução normal de acetato de amônio pH 7,0, e determinação de seus teores no extrato. A acidez potencial $(\mathrm{H}+\mathrm{Al})$ foi feita pela extração com solução tamponada de acetato de cálcio a pH 7,0 e titulação alcalimétrica do extrato. A CTC total foi calculada pelo somatório das bases mais a acidez potencial.

\subsubsection{4 Óxidos de ferro e alumínio cristalinos}

Os teores de óxidos cristalinos foram obtidos em meio tamponado (bicarbonato $\mathrm{pH} 7,3$ ) pela redução com ditionito e complexação com citrato com extrações sucessivas até coloração acinzentada da amostra, que variou com o solo, em banho-maria, sob agitação, e centrifugação. A determinação quantitativa do ferro solubilizado foi efetuada por espectrometria de emissão atômica por plasma de argônio com acoplamento indutivo (ICP-AES).

\subsubsection{Cádmio total}

Para a digestão do $\mathrm{Cd}$ total adotou-se a técnica de microondas em sistema fechado sob pressão (que diminui o tempo de digestão) pesando-se $0,50 \mathrm{~g}$ de solo em papel manteiga colocando-o em frascos de teflon acrescentando-se em cada um $10 \mathrm{ml}$ de ácido nítrico $65 \%$ e colocando-os no microondas modelo USEPA 3051. Lavou-se a tampa dos frascos com água deionizada, passandose o conteúdo para balão de $50 \mathrm{ml}$. Completou-se o volume para $50 \mathrm{ml}$ com água deionizada, filtrando-se e acondicionando-se em frascos de vidro bem tampados. Logo após foi realizada a determinação da concentração de Cd total diretamente dos extratos pela espectrometria de emissão atômica por plasma 
de argônio com acoplamento indutivo (ICP-AES). Essa técnica tem se mostrado eficiente por possibilitar análises multielementares com uma faixa analítica de trabalho mais ampla, dispensando diluições, e com limites de detecção iguais ou melhores que a absorção atômica, sendo praticamente isenta de interferências espectrais (Abreu, 1997).

Convencionalmente esta análise exige digestão com ácido fluorídrico (HF) juntamente com outros ácidos fortes. Entretanto o uso de HF assim como água régia na rotina dos laboratórios não é recomendado, pois são corrosivos e de difícil manuseio trazendo perigo de acidente de trabalho. Por isso, no lugar de ambos usou-se ácido nítrico para a realização da digestão por trazer menor perigo e pela obtenção de valores bem próximos aos totais, sendo suficientes para diagnosticar os níveis de contaminação dos metais nos solos (Abreu et al., 1996). Além disso, o ácido nítrico é um forte agente oxidante, os sais de nitrato são bastante solúveis e não formam complexos. Quando empregado em sistemas sob pressão, o ponto de ebulição do ácido nítrico pode alcançar até $170^{\circ} \mathrm{C}$ e, assim, aumentar o potencial de oxidação e velocidade de reação (Abreu, 1997).

\subsection{Extratores de cádmio estudados}

Os extratores DTPA-TEA pH 7,3, Mehlich 3 e $\mathrm{CaCl}_{2} 0,01 \mathrm{~mol} \mathrm{~L}^{-1}$ foram os escolhidos para o estudo neste trabalho, e são chamados aqui de convencionais. Todas as extrações foram feitas em triplicatas e os valores aqui apresentados correspondem às médias obtidas.

\subsubsection{Mehlich 3}

Este método de extração, que usa como solução extratora a solução de

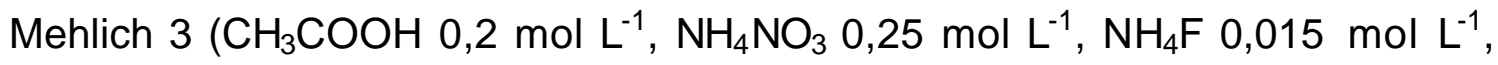


$\mathrm{HNO}_{3} 0,013 \mathrm{~mol} \mathrm{~L}^{-1}$, EDTA $0,001 \mathrm{~mol} \mathrm{~L}^{-1} \mathrm{pH} 2,5 \pm 0,1$ ), tem por princípio a solubilização e quelação dos elementos.

Para o preparo da solução estoque de fluoreto/EDTA usou-se um balão volumétrico de $1 \mathrm{~L}$, e a ele adicionaram-se $600 \mathrm{ml}$ de água deionizada e 138,9 g de $\mathrm{NH}_{4} \mathrm{~F}$. Misturou-se bem. Em seqüência, dissolveram-se 73,05 g de EDTA completando-se o volume para $1 \mathrm{~L}$ com água deionizada. Para o preparo da solução de Mehlich-3 colocaram-se $1600 \mathrm{ml}$ de água deionizada em um balão volumétrico de $2.000 \mathrm{ml}$. Adicionaram-se $40 \mathrm{~g}$ de $\mathrm{NH}_{4} \mathrm{NO}_{3}$ e $8 \mathrm{ml}$ da solução estoque fluoreto/EDTA preparada anteriormente. Misturou-se. Adicionaram-se 22,856 ml de ácido acético glacial e 1,64 ml de ácido nítrico p.a. Completou-se o volume para $2.000 \mathrm{ml}$ com água deionizada. $\mathrm{O}$ pH da solução foi aferido para $2,5 \pm 0,1$

A extração foi realizada agitando-se $2,5 \mathrm{~g}$ de TFSA com $25 \mathrm{ml}$ da solução extratora (Mehlich 3 ) durante cinco minutos. Usou-se agitador horizontal a 240rpm. Filtrou-se o extrato em papel de filtro Framex faixa azul. A determinação quantitativa do cádmio foi efetuada pelo ICP-AES.

\subsubsection{DTPA-TEA pH 7,3}

O princípio do método utilizando a solução de DTPA-TEA pH 7,3 (ácido dietilenotriaminopentacético - DTPA 0,005 $\mathrm{mol} \mathrm{L}^{-1}+$ trietanolamina - TEA 0,1 mol L $\mathrm{L}^{-1}+$ cloreto de cálcio $0,01 \mathrm{~mol} \mathrm{~L}^{-1}$ ) é a complexação dos metais. $\mathrm{O}$ agente extrator reage com os íons livres de $\mathrm{Cd}$ formando complexos solúveis, o que resulta em redução da atividade dos metais livres em solução. Em resposta, íons desses metais desprendem da superfície das partículas do solo ou dissolvem da fase sólida para restabelecer o equilíbrio na solução.

Preparou-se a solução extratora DTPA-TEA pH 7,3 adicionando-se em um béquer aproximadamente $200 \mathrm{ml}$ de água deionizada, 1,96g de DTPA e 14,9 ml de trietanolamina. Agitou-se e logo após foi adicionado $1,47 \mathrm{~g}$ de $\mathrm{CaCl}_{2} \cdot 2 \mathrm{H}_{2} \mathrm{O}$. 
Transferiu-se para balão volumétrico de $1 \mathrm{~L}$ completando-se o volume com água deionizada. $\mathrm{O} \mathrm{pH}$ da solução foi corrigido, quando necessário, com solução de ácido clorídrico $4 \mathrm{~mol} \mathrm{~L}^{-1}$.

Foram pesados $10 \mathrm{~g}$ de solo e colocados em tubos de centrifuga de polipropileno com capacidade para $47,5 \mathrm{ml}$. Adicionaram-se $20 \mathrm{ml}$ da solução extratora de DTPA (ácido dietilenotriaminopentacético - DTPA 0,005 $\mathrm{mol} \mathrm{L}^{-1}+$ trietanolamina - TEA $0,1 \mathrm{~mol} \mathrm{~L}^{-1}$ + cloreto de cálcio $0,01 \mathrm{~mol} \mathrm{~L}^{-1}$ ), a pH 7,3. Os tubos foram tampados e agitados por $2 \mathrm{~h}$ a $220 \mathrm{rpm}$ e, filtradas as suspensões imediatamente. A determinação quantitativa do cádmio foi efetuada por espectrometria de emissão atômica por plasma induzido de argônio (ICP-AES).

\subsection{3 $\mathrm{CaCl}_{2} 0,01 \mathrm{~mol} \mathrm{~L}^{-1}$}

A relação solo:solução adotada neste trabalho foi de $1 \mathrm{~g}$ de solo para $10 \mathrm{ml}$ de $\mathrm{CaCl}_{2}$ 0,01 mol L-1 por $2 \mathrm{~h}$ de agitação. Logo após a agitação as suspensões foram filtradas e determinadas por espectrometria de emissão atômica por plasma (ICP-AES). A adoção da relação e tempo de agitação apoiou-se no trabalho de Maiz (1997).

\subsubsection{Cálculo do limite de detecção para um ICP-AES}

Com o intuito de se verificar a validade dos resultados obtidos da extração de $\mathrm{Cd}$ dos solos estudados pelo uso dos extratores químicos convencionais, foi calculado o limite de detecção para o ICP-AES utilizado neste trabalho.

O limite de detecção é uma consideração importante, pois nos fornece a possibilidade de analisar com boa precisão um elemento com baixo nível de concentração. Convencionalmente o limite de detecção para um determinado 
elemento é a quantidade mínima ou concentração que pode ser detectada por um dado procedimento analítico (Abreu, 1997).

Por meio de cálculo numérico pode-se estabelecer o limite de detecção como:

$$
C_{L}=\frac{k \sigma_{b}}{S}
$$

onde: $\mathrm{G}$ é o limite de detecção, $\sigma_{b}$ é o desvio padrão do branco, $S$ é a sensibilidade do método (coeficiente angular da curva de calibração) e k é uma constante.

$O$ valor de $k$ utilizado foi 3 pois tem se mostrado uma opção mais apropriada. O desvio padrão foi determinado pela medida da variação do sinal, usando uma solução do branco, fazendo com que a equação fique limitada ao ruído. Assim, foram feitas quinze determinações do sinal de fundo para determinação do desvio padrão para cada extrator convencional utilizado neste estudo.

\subsubsection{Emprego dos ácidos orgânicos}

Segundo Wolt (1994) as concentrações dos ácidos acético, cítrico e oxálico na solução do solo varia de 2,65-5,7; 0,014-0,21 e 0,004-1,04 mmol L-1 respectivamente. Para este estudo foi testada a potencialidade de extração de Cd por estes ácidos e as concentrações sugeridas por Wolt (1994) foram multiplicadas por dez uma vez que se busca verificar a extratabilidade destes ácidos quando comparado com os extratores químicos convencionais, como DTPA-TEA pH 7,3, Mehlich 3 e $\mathrm{CaCl}_{2} 0,01 \mathrm{~mol} \mathrm{~L}^{-1}$ tendo então para ácido acético $57 \mathrm{mmol} \mathrm{L}^{-1}$, ácido cítrico $2,1 \mathrm{mmol} \mathrm{L}^{-1}$ e ácido oxálico $10,4 \mathrm{mmol} \mathrm{L}^{-1}$. 


\subsubsection{1 Ácido acético}

Para estimar a extratabilidade de $\mathrm{Cd}$ dos solos pelo emprego do ácido acético preparou-se uma solução de ácido acético $57 \mathrm{mmol} \mathrm{L}^{-1}$.

Pesaram-se $10 \mathrm{~g}$ das amostras dos solos em estudo sendo colocadas em tubos de polipropileno com rosca e a elas foram acrescidos $20 \mathrm{ml}$ da solução extratora de ácido acético. Os tubos foram agitados por $2 \mathrm{~h}$ a $220 \mathrm{rpm}$ e as suspensões colocadas para filtrar imediatamente. Logo após foi realizada determinação quantitativa do $\mathrm{Cd}$ por espectrometria de emissão atômica por plasma (ICP-AES). Seguiu-se a mesma metodologia adotada para estimar o $\mathrm{Cd}$ por DTPA-TEA a pH 7,3 usando-se a mesma relação solo:solução e o mesmo tempo de agitação.

\subsubsection{2 Ácido cítrico}

Para estimar a extratabilidade de $\mathrm{Cd}$ dos solos pelo emprego do ácido cítrico preparou-se uma solução de ácido cítrico $2,1 \mathrm{mmol} \mathrm{L}^{-1}$.

Pesaram-se $10 \mathrm{~g}$ das amostras dos solos em estudo sendo colocadas em tubos de polipropileno com rosca e a elas acrescidos $20 \mathrm{ml}$ da solução extratora de ácido acético. Os tubos foram agitados por $2 \mathrm{~h}$ a $220 \mathrm{rpm}$ e as suspensões colocadas para filtrar imediatamente. Logo após foi realizada determinação quantitativa do Cd por espectrometria de emissão atômica por plasma (ICPAES). Seguiu-se a mesma metodologia adotada para estimar o Cd por DTPA a pH 7,3 somente para comparação. 


\subsubsection{3 Ácido oxálico}

A capacidade do ácido oxálico em extrair $\mathrm{Cd}$ das amostras de solos foi medida pelo uso de $20 \mathrm{ml}$ de solução de ácido oxálico $10,4 \mathrm{mmol} \mathrm{L}^{-1}$. A metodologia de extração foi a mesma dos dois casos anteriores.

\subsection{Análises estatísticas}

Com os resultados obtidos foram feitas análises de regressões simples e múltiplas, para se determinarem quais os atributos que mais se correlacionaram com o Cd extraído pelos extratores convencionais nas amostras dos solos naturais. Para esta análise foi utilizado o programa MINITAB Release 13,0 Statistical Software. Foi adotado para estas análises um nível de significância de $10 \%$.

O teste de média de comparação (teste Tukey) foi realizado dentro dos solos naturais estudados, dos métodos convencionais de extração de $\mathrm{Cd}$ e entre os solos e os tratamentos. Para este teste foi utilizado o programa SAS

Release 6.11. Os resultados destas análises estatisticas foram anexados ao trabalho. 


\section{RESULTADOS E DISCUSSÃO}

\subsection{Solos utilizados}

Os solos do presente estudo foram escolhidos e reunidos em dois grupos. Um grupo constituído por quinze solos bem caracterizados e que foram usados para estudar: a) a extração do cádmio por três extratores convencionais e relação com alguns de seus atributos físicos e químicos e b) três ácidos orgânicos de baixo peso molecular, como representando uma simulação de uma solução de solo perto da zona radicular. Para a situação (a) com auxílio de regressão simples e múltipla, verificou-se a influência de diversos atributos do solo como teor de argila, matéria orgânica, ferro livre, Cd total, CTC e pH em $\mathrm{KCl} 1 \mathrm{~mol} \mathrm{~L}^{-1}$ na extratabilidade do Cd nos três extratores convencionais.

No segundo grupo, em amostras sabidamente com algum tipo de contaminação, estudou-se a extração pelos seis extratores e procurou-se relacionar os teores extraídos por eles.

\subsection{Análises químicas}

\subsubsection{Análises químicas de rotina}

Observou-se grande heterogeneidade nas condições gerais de fertilidade dos solos naturais baseado nos valores obtidos de $\mathrm{pH}$ em água e $\mathrm{KCl} 1 \mathrm{~mol} \mathrm{~L}^{-1}$, teores de $\mathrm{Ca}, \mathrm{Mg}, \mathrm{K}, \mathrm{Na}, \mathrm{Al}$, acidez potencial, CTC, carbono orgânico e 
saturação por bases por meio de caracterização química das amostras estudadas conforme mostra a tabela 1. A tabela 2 apresenta os teores totais de ferro e alumínio obtidos por ataque sulfúrico que foram úteis por ocasião da classificação dos solos.

Os solos LVef, PVAe e NVef foram aqueles dentre os naturais que apresentaram maior fertilidade, destacando-se o LVef, que apresenta uma saturação por bases de $86 \%$. A saturação por bases é um excelente indicativo das condições gerais da fertilidade do solo fornecendo uma idéia do estado de ocupação das cargas da CTC total, ou seja, do total de cargas negativas existentes no solo, qual a proporção ocupada pelos cátions úteis ( $\mathrm{Ca}, \mathrm{Mg}$ e $\mathrm{K}$ ) (Tomé Jr, 1997). Solos que apresentam uma saturação por bases maior do que $50 \%$ são considerados eutróficos o que reflete boa fertilidade (Raij et al., 1997). Além disso, os solos LVef e NVef, com caráter oxídico, mostram alto teor de $\mathrm{Mg}$ (Embrapa, 1999). Os outros solos apresentaram baixa saturação por base destacando-se entre eles os solos PVAd-1, RQo, LVAd-1, LVAd-2 e LVAw mostrando-se todos com caráter distrófico. Todos estes cinco solos são altamente intemperizados.

O cálculo da saturação por bases $(\mathrm{V} \%)$ requer o conhecimento da carga negativa total existente no solo (CTC total). Embora existam metodologias de determinação direta da CTC total, no Brasil ela é freqüentemente calculada somando-se as cargas dos cátions $(\mathrm{K}, \mathrm{Ca}, \mathrm{Mg}$ e $\mathrm{Al})$ com os $\mathrm{H}^{+}$não trocáveis. Por isso, a necessidade da determinação da chamada acidez potencial ( soma das cargas devidas ao Al e ao H) (Tomé Jr., 1997). Os solos apresentaram alta acidez potencial com exceção do PVAe onde ela foi média.

A caracterização química também foi realizada para as amostras de solos contaminados. A tabela 3 apresenta os dados da análise de rotina das amostras de solos de regiões que sofreram algum tipo de contaminação.

A observação da tabela 3 permite verificar que a faixa de $\mathrm{pH}$ em $\mathrm{KCl} 1 \mathrm{~mol}$ $\mathrm{L}^{-1}$ (atributo muito usado em levantamentos pedológicos) das amostras variou de 4,2 a 7,0 tendo apresentado valores bem próximos aos obtidos para as 
Tabela 1. Caracterização química das amostras dos solos naturais

\begin{tabular}{|c|c|c|c|c|c|c|c|c|c|c|c|c|c|}
\hline Amostra & $\mathrm{pH} \mathrm{H}_{2}$ & $\mathrm{Cl} 1 \mathrm{~mol} \mathrm{~L}^{-1}$ & delta $\mathrm{pH}$ & $\mathrm{Ca}$ & $\mathrm{Mg}$ & K & $\begin{array}{l}\mathrm{Na} \\
\mathrm{mmo}\end{array}$ & $\mathrm{Al}$ & $\mathrm{H}+\mathrm{Al}$ & CTC & $\begin{array}{c}\mathrm{C} \\
\mathrm{g} \mathrm{kg}^{-1}\end{array}$ & $\begin{array}{c}\mathrm{SB} \\
\mathrm{mmol}_{\mathrm{c}} \mathrm{kg}^{-1}\end{array}$ & $\begin{array}{l}\mathrm{V} \\
\%\end{array}$ \\
\hline $\mathrm{LVj}$ & 6,5 & 5,7 & $-0,8$ & 22 & 7 & 0,6 & 5,4 & 1 & 37 & 72 & 21 & 35,0 & 48 \\
\hline LAw & 5,5 & 4,6 & $-0,9$ & 11 & 4 & 0,3 & 3,0 & 3 & 25 & 43 & 20 & 18,3 & 42 \\
\hline PVAe & 6,5 & 6,1 & $-0,4$ & 9 & 4 & 0,5 & 1,4 & 0 & 10 & 25 & 3 & 14,9 & 59 \\
\hline PVAd-1 & 4,8 & 3,9 & $-0,9$ & 5 & 1 & 0,4 & 1,3 & 16 & 40 & 48 & 11 & 7,7 & 16 \\
\hline PVAd-2 & 5,7 & 5,0 & $-0,7$ & 10 & 4 & 0,4 & 2,6 & 1 & 24 & 40 & 10 & 17,0 & 39 \\
\hline LVdf-2 & 5,9 & 4,9 & $-1,0$ & 15 & 5 & 0,3 & 2,6 & 1 & 41 & 64 & 13 & 22,9 & 35 \\
\hline LVAd-1 & 4,7 & 3,8 & $-0,9$ & 1 & 0 & 0,3 & 0,7 & 14 & 37 & 39 & 9 & 2,0 & 5 \\
\hline LVAd-2 & 4,7 & 4,2 & $-0,5$ & 2 & 1 & 0,5 & 1,6 & 27 & 110 & 115 & 21 & 5,1 & 4 \\
\hline LVAw & 4,4 & 4,1 & $-0,3$ & 0 & 0 & 0,9 & 0,3 & 13 & 36 & 37 & 10 & 1,2 & 3 \\
\hline NVef & 6,4 & 5,6 & $-0,8$ & 60 & 18 & 0,6 & 8,0 & 1 & 41 & 128 & 27 & 86,6 & 67 \\
\hline RQo & 5,5 & 4,3 & $-1,2$ & 2 & 0 & 0,3 & 0,6 & 3 & 16 & 19 & 3 & 2,9 & 15 \\
\hline
\end{tabular}


Tabela 2. Silício, alumínio, ferro, titânio e manganês presentes nas amostras dos solos naturais obtidos por ataque sulfúrio, além dos índices Ki e Kr

\begin{tabular}{|c|c|c|c|c|c|c|c|}
\hline Amostra & $\mathrm{SiO}_{2}$ & $\mathrm{Al}_{2} \mathrm{O}_{3}$ & $\begin{array}{c}\mathrm{Fe}_{2} \mathrm{O}_{3} \\
-\mathrm{g} \mathrm{kg}^{-1}\end{array}$ & $\mathrm{TiO}_{2}$ & $\mathrm{MnO}$ & $\mathrm{Ki}$ & $\mathrm{Kr}$ \\
\hline LVj & 109,00 & 237,60 & 373,20 & 47,50 & 1,6 & 0,78 & 0,39 \\
\hline LVef & 101,00 & 190,70 & 268,10 & 43,70 & 1,5 & 0,90 & 0,47 \\
\hline LAw & 72,00 & 120,90 & 83,40 & 18,60 & 0,2 & 1,01 & 0,70 \\
\hline PVAe & 23,00 & 20,90 & 24,70 & 6,80 & 0,3 & 1,87 & 1,07 \\
\hline PVAd-1 & 38,00 & 26,50 & 7,80 & 1,10 & 0,1 & 2,44 & 2,05 \\
\hline PVAd-2 & 111,00 & 117,30 & 142,80 & 18,60 & 1,2 & 1,61 & 0,90 \\
\hline LVd & 76,00 & 115,20 & 100,10 & 19,10 & 0,3 & 1,12 & 0,72 \\
\hline LVdf-1 & 145,00 & 232,00 & 289,20 & 28,50 & 1,5 & 1,06 & 0,59 \\
\hline LVdf-2 & 123,00 & 187,70 & 215,90 & 22,50 & 1,7 & 1,11 & 0,64 \\
\hline LVAd-1 & 51,00 & 48,40 & 14,30 & 1,40 & 0,1 & 1,79 & 1,51 \\
\hline LVAd-2 & 186,00 & 243,20 & 96,00 & 8,00 & 0,1 & 1,30 & 1,04 \\
\hline LVAw & 61,00 & 65,30 & 23,00 & 3,60 & 0,1 & 1,59 & 1,30 \\
\hline NVef & 172,00 & 182,00 & 349,60 & 42,70 & 2,6 & 1,61 & 0,72 \\
\hline RQo & 25,00 & 4,10 & 4,40 & 0,90 & 0,1 & 10,37 & 6,15 \\
\hline SXd & 101,00 & 52,00 & 45,40 & 3,90 & 2,8 & 3,30 & 2,12 \\
\hline
\end{tabular}


amostras naturais. Observou-se certa variabilidade na faixa de valores de $\mathrm{pH}$ variando de uma acidez fraca até uma alcalinidade fraca (Tomé Jr., 1997). Todas as amostras apresentaram valores de carga líquida negativa o que facilitaria a adsorção do Cd por se tratar de um cátion metálico, dificultando consequentemente a sua extração em soluções salinas diluídas.

As amostras AM1 e AM3 foram as que mostraram maiores valores para CTC e V\%, enquanto que as demais mostraram baixos valores de saturação por bases.

\subsection{Variáveis independentes estudadas}

Com o propósito de se relacionar o teor de Cd extraído, das quinze amostras dos solos naturais, por cada extrator convencional, Mehlich 3, DTPATEA pH 7,3 e $\mathrm{CaCl}_{2}$ 0,01 mol L-1, com alguns dos seus atributos mais importantes e de fácil determinação, selecionaram-se entre eles os seguintes: argila, matéria orgânica, $\mathrm{CTC}, \mathrm{Fe}_{d}$, Cd total e $\mathrm{pH}$ em KCl $1 \mathrm{~mol} \mathrm{~L}^{-1}$. Como pode ser observado na tabela 4 , todos os atributos mostraram uma ampla faixa de variação dos valores em virtude da grande heterogeneidade apresentada pelas quinze amostras dos solos naturais escolhidos. Os valores destes atributos foram utilizados na análise estatística para a realização da análise de regressão simples e múltipla, além do teste de comparação de médias (Tukey). 
Tabela 3. Caracterização química das amostras dos solos contaminados

\begin{tabular}{|c|c|c|c|c|c|c|c|c|c|c|c|c|c|}
\hline Amostra & \multicolumn{3}{|c|}{$\mathrm{pH} \mathrm{H}_{2} \mathrm{O} \mathrm{pH} \mathrm{KCl} 1 \mathrm{~mol} \mathrm{~L}^{-1}$ delta $\mathrm{pH}$} & $\mathrm{Ca}$ & $\mathrm{Mg}$ & $\mathrm{K}$ & $\begin{array}{c}\mathrm{Na} \\
\mathrm{mol}_{\mathrm{C}}\end{array}$ & $\mathrm{Al}$ & $\mathrm{H}+\mathrm{Al}$ & CTC & $\frac{\mathrm{C}}{\mathrm{g} \mathrm{kg}^{-1}}$ & $\begin{array}{c}\mathrm{SB} \\
\mathrm{mmol}_{\mathrm{c}} \mathrm{kg}^{-1}\end{array}$ & $\begin{array}{l}\mathrm{V} \\
\%\end{array}$ \\
\hline AM1 & 7,6 & 7,0 & $-0,6$ & 47 & 4 & 3,0 & 3,7 & 1 & 1 & 58 & 13 & 57,7 & 98 \\
\hline AM2 & 5,5 & 4,2 & $-1,3$ & 8 & 7 & 0,9 & 3,2 & 27 & 57 & 19 & 18 & 19,1 & 25 \\
\hline AM3 & 6,9 & 6,2 & $-0,7$ & 22 & 7 & 2,9 & 2,3 & 0 & 4 & 34 & 5 & 34,2 & 89 \\
\hline AM4 & 5,0 & 4,3 & $-0,7$ & 4 & 2 & 0,3 & 1,0 & 13 & 61 & 7 & 18 & 7,3 & 10 \\
\hline AM5 & 4,9 & 4,2 & $-0,7$ & 3 & 2 & 1,0 & 0,3 & 13 & 39 & 6 & 11 & 6,3 & 13 \\
\hline AM6 & 4,8 & 4,3 & $-0,5$ & 5 & 4 & 1,8 & 0,4 & 9 & 43 & 11 & 18 & 11,2 & 20 \\
\hline AM7 & 5,8 & 5,3 & $-0,5$ & 15 & 6 & 2,5 & 0,5 & 1 & 22 & 24 & 16 & 24,0 & 52 \\
\hline AM8 & 5,9 & 5,2 & $-0,7$ & 14 & 5 & 2,1 & 0,4 & 1 & 21 & 22 & 14 & 21,5 & 50 \\
\hline
\end{tabular}


Tabela 4. Atributos dos solos naturais usados como variáveis independentes

\begin{tabular}{|c|c|c|c|c|c|c|c|}
\hline amostra & $\begin{array}{l}\text { argila } \\
\mathrm{g} \mathrm{kg}^{-1}\end{array}$ & $\begin{array}{c}\text { CTC } \\
{\text { mmolc } \mathrm{kg}^{-1}}^{-}\end{array}$ & $\begin{array}{c}\mathrm{C} \\
\mathrm{g} \mathrm{kg}^{-1}\end{array}$ & $\mathrm{pH} \mathrm{KCl} 1 \mathrm{~mol} \mathrm{~L}^{-}$ & $\mathrm{Fe}_{\mathrm{d}}$ & $\mathrm{Al}_{\mathrm{d}}$ & $\begin{array}{c}\text { Cd Total } \\
\mathrm{mg} \mathrm{kg}^{-1} \\
\end{array}$ \\
\hline $\mathrm{LVj}$ & 520 & 72 & 21 & 5,7 & 119,2 & 47,5 & 0,10 \\
\hline LVef & 510 & 150 & 14 & 6,3 & 73,1 & 36,6 & 0,30 \\
\hline LAw & 260 & 43 & 20 & 4,6 & 24,3 & 33,7 & 0,00 \\
\hline PVAe & 60 & 25 & 3 & 6,1 & 3,1 & 0,0 & 0,04 \\
\hline PVAd-1 & 90 & 48 & 11 & 3,9 & 1,5 & 0,6 & 0,71 \\
\hline PVAd-2 & 290 & 40 & 10 & 5,0 & 25,5 & 11,4 & 1,04 \\
\hline LVd & 310 & 55 & 16 & 5,1 & 36,5 & 21,6 & 1,58 \\
\hline LVdf-1 & 610 & 43 & 7 & 5,6 & 118,6 & 39,9 & 2,01 \\
\hline LVdf-2 & 540 & 64 & 13 & 4,9 & 86,0 & 41,1 & 2,23 \\
\hline LVAd-1 & 110 & 39 & 9 & 3,8 & 3,1 & 2,1 & 0,96 \\
\hline LVAd-2 & 600 & 115 & 21 & 4,2 & 39,2 & 56,1 & 1,60 \\
\hline LVAw & 180 & 37 & 10 & 4,1 & 6,3 & 6,7 & 1,44 \\
\hline NVef & 500 & 128 & 27 & 5,6 & 112,3 & 48,4 & 1,88 \\
\hline RQo & 20 & 19 & 3 & 4,3 & 0,3 & 2,3 & 1,00 \\
\hline SXd & 270 & 83 & 17 & 4,0 & 9,7 & 3,5 & 1,48 \\
\hline
\end{tabular}




\subsubsection{Análise física}

Os resultados da análise física encontram-se na tabela 4. De maneira geral, os teores de argila estão bem distribuídos. Os solos LVj, LVef, LVdf-2, LVAd-2 e NVef apresentaram altos teores de argila, com destaque para o LVdf-1. O RQo foi o que apresentou o menor teor. Dos três Argissolos, os PVAe e PVAd-1 foram os que apresentaram baixos teores sendo que o PVAd-2 apresentou teor médio. É esperado que os solos que apresentam maiores teores de argila adsorvam mais $\mathrm{Cd}$, graças à maior superfície exposta, o que dificultaria a extração do Cd pelos extratores. Isto estaria de acordo com Kort et al. (1976) que observaram que a argila foi um dos atributos que melhor se correlacionou com a retenção do Cd.

\subsubsection{Carbono orgânico}

$\mathrm{Na}$ tabela 4 são ainda mostrados os teores de carbono orgânico das amostras dos solos naturais estudados. Observou-se que os solos que apresentaram maior teor foram os LVj, LAw, LVAd-2 e NVef, acompanhados de uma alta acidez potencial. Este elevado teor de matéria orgânica pode influenciar na fixação do Cd nestes solos, dificultando a extração do elemento, concordando com Singh (1979) e Petruzzelli et al. (1985), que verificaram que solos que apresentam maior teor de matéria orgânica e consequentemente maior CTC, mostraram uma maior adsorção de cádmio, principalmente em superfície, pois é nesta camada que se encontram os maiores valores para estes atributos e portanto, maior quantidade de cargas negativas. 


\subsubsection{CTC}

Os valores de CTC dos solos naturais encontram-se também na tabela 4. Observou-se que assim como o teor de carbono orgânico, os solos que apresentaram maior CTC foram os LVj, LAw, LVAd-2 e NVef, o que já era esperado pois altos teores de carbono orgânico levam a altos teores de matéria orgânica e, consequentemente, a alta CTC. A CTC também pode influenciar na retenção do elemento em estudo. Esta afirmativa concorda com Dias (1999) que mostrou que a CTC foi o atributo que teve o maior efeito sobre a adsorção de Cd para um Nitossolo Vermelho eutroférrico e dois Latossolos do estado de São Paulo.

\subsubsection{Ferro e alumínio solúveis em ditionito-citrato-bicarbonato (DCB)}

$\mathrm{Na}$ tabela 4 encontram-se os teores de ferro e alumínio solúveis em DCB $\left(\mathrm{Fe}_{\mathrm{d}}\right.$ e $\left.\mathrm{Al}_{\mathrm{d}}\right)$ dos solos naturais utilizados nas análises de regressão.

No tocante ao ferro (tabela 4) destacam-se os solos LVj, LVef, LVdf-1, LVdf2 e NVef. Este fato já era esperado por se tratarem de Latossolos e de um Nitossolo que apresentam teores muito elevados de óxidos de ferro e alumínio totais.

A quantidade elevada dos teores de ferro e alumínio em formas cristalinas indicam o alto grau de intemperismo desses solos, pois os Latossolos apresentam uma evolução muito avançada com a atuação do processo de dessilicatização, levando a um acúmulo de óxidos e hidróxidos de ferro e alumínio. Os altos teores de ferro podem levar a uma adsorção específica do Cd formando complexos de esfera interna entre a superfície destes óxidos com o metal, concordando com McBride (1989) que verificou grande especificidade dos óxidos por certos metais pesados e com Gadde \& Laitinen (1989) que mostraram adsorção específica de $\mathrm{Cd}^{2+}$ em óxido férrico. 


\subsubsection{Cd total}

$\mathrm{Na}$ tabela 4 encontram-se os valores de $\mathrm{Cd}$ total obtidos das amostras naturais por digestão com ácido nítrico $65 \%$ em microondas. Foi possível detectar o $\mathrm{Cd}$ total em todas as amostras naturais, embora obtendo valores muito baixos deste elemento, o que já era esperado justamente por se tratar de solos naturais. Os teores totais de $\mathrm{Cd}$ estão dentro do limite padrão estabelecido pela USEPA, e pela Diretriz da Comunidade Européia (Hall, 1998). Os valores de $\mathrm{Cd}$ total obtidos por digestão com ácido nítrico para o LVj, LAw e PVAe apresentaram-se menores do que os teores de Cd obtidos por extração pelo uso dos extratores convencionais. Isto poderia estar relacionado com algum erro de leitura do aparelho ou a alguma interferência não detectada na determinação do elemento.

Nas amostras contaminadas também foram feitos os teores de $\mathrm{Cd}$ total sendo encontrados os seguintes valores nas amostras AM1 a AM8, respectivamente, 114,$5 ; 1,74 ; 1,51 ; 0,67 ; 0,37 ; 0,50 ; 0,66$ e $0,20 \mathrm{mg} \mathrm{Cd} \mathrm{kg}^{-1}$. Observando o valor de Cd total obtido na amostra 1 e seguindo-se os limites estabelecidos pela USEPA e pela Diretriz da Comunidade Européia a área de onde se retirou a amostra 1 pode ser considerada uma área poluída.

É bem reconhecido que o teor total não é um índice satisfatório para medir a biodisponibilidade de um elemento, em razão do diferente e complexo modelo de distribuição dos elementos dentre as diferentes espécies químicas ou fases sólidas nos solos (Chen et al., 1996). Contudo, este dado fornece informações quanto ao acúmulo do elemento ao longo do tempo.

\subsection{6 $\mathrm{pH} \mathrm{em} \mathrm{KCl} 1 \mathrm{~mol} \mathrm{~L}^{-1}$}

A medida do $\mathrm{pH}$ em KCl $1 \mathrm{~mol} \mathrm{~L}^{-1}$ reflete um conjunto complexo de reações no sistema solo-solução e muito útil quando associada a atributos do solo. 
A faixa de $\mathrm{pH}$ em KCl $1 \mathrm{~mol} \mathrm{~L}^{-1}$ (tabela 4) mostrou-se ampla para as amostras dos solos naturais compreendendo valores de 3,8 a 6,3. Observando estes valores nota-se que a acidez nestes solos encontra-se de fraca a elevada. Estes valores podem influenciar na extração do $\mathrm{Cd}$ na medida em que o pH ao diminuir, torna o Cd mais solúvel, concordando com Barrow et al. (1989) que verificaram que o pH altera a adsorção de cádmio em virtude do seu efeito sobre o potencial elétrico e que assim, a adsorção de Cd aumenta com a elevação do $\mathrm{pH}$.

Utilizando-se a diferença entre o $\mathrm{pH}$ em água e o $\mathrm{pH}$ em KCl $1 \mathrm{~mol} \mathrm{~L}^{-1}$, temos o delta $\mathrm{pH}$, podendo-se por meio dele obter uma estimativa da carga líquida do solo (Tomé Jr., 1997). Assim, tem-se:

$$
\Delta \mathrm{pH}=\mathrm{pH} \mathrm{KCl}-\mathrm{pH} \text { água }
$$

Ao calcular-se esta diferença para as amostras dos solos estudados observou-se que estes solos apresentam predominância de cargas negativas, adsorvendo portanto, maior quantidade de cátions do que de ânions.

\subsection{Influência de atributos do solo na extração do $\mathrm{Cd}$ pelos três extratores convencionais}

\subsubsection{Análise de correlação simples entre DTPA-TEA pH 7,3, Mehlich 3 $\mathrm{CaCl}_{2}$ 0,01 mol L-1 e atributos do solo}

Os resultados da extração do cádmio das amostras dos solos naturais pelos extratores convencionais, Mehlich 3, DTPA-TEA pH 7,3 e $\mathrm{CaCl}_{2} 0,01 \mathrm{~mol} \mathrm{~L}^{-1}$ encontram-se na tabela 5. 
Tabela 5. Teores de cádmio nas amostras dos solos naturais usando os extratores convencionais. Média de três repetições.

\begin{tabular}{|c|c|c|c|c|}
\hline $\begin{array}{c}\text { L.D. } \\
\mathrm{mg} \mathrm{kg}^{-1}\end{array}$ & 0,03 & 0,03 & 0,03 & \\
\hline Solos & Mehlich 3 & $\begin{array}{c}\text { DTPA } \\
\text { Cd } \\
-\quad \mathrm{mg} \mathrm{kg}^{-1}\end{array}$ & $\mathrm{CaCl}_{2}$ & Cd Total \\
\hline LVj & 0,07 & 0,21 & 0,07 & 0,10 \\
\hline LVef & 0,07 & 0,11 & 0,07 & 0,30 \\
\hline LAw & 0,09 & 0,24 & 0,07 & 0,00 \\
\hline PVAe & 0,01 & 0,26 & 0,07 & 0,04 \\
\hline PVAd-1 & 0,05 & 0,41 & 0,07 & 0,71 \\
\hline PVAd-2 & 0,03 & 0,18 & 0,07 & 1,04 \\
\hline LVd & 0,11 & 0,11 & 0,07 & 1,58 \\
\hline LVdf-1 & 0,02 & 0,00 & 0,07 & 2,01 \\
\hline LVdf-2 & 0,03 & 0,08 & 0,07 & 2,23 \\
\hline LVAd-1 & 0,02 & 0,14 & 0,07 & 0,96 \\
\hline LVAd-2 & 0,08 & 0,13 & 0,07 & 1,60 \\
\hline LVAw & 0,27 & 0,19 & 0,07 & 1,44 \\
\hline NVef & 0,08 & 0,11 & 0,07 & 1,88 \\
\hline RQo & 0,06 & 0,46 & 0,07 & 1,00 \\
\hline SXd & 0,07 & 0,38 & 0,07 & 1,48 \\
\hline
\end{tabular}

L.D.: Limite de detecção calculado para o ICP-AES

Observou-se que o teor do elemento extraído pela solução de Mehlich 3 variou de 0,01 a $0,27 \mathrm{mg} \mathrm{kg}^{-1}$ nas amostras dos solos naturais. Para os solos PVAe, PVAd-2, LVdf-1, LVdf-2 e LVAd-1 os valores do Cd extraído por Mehlich 3 ficaram abaixo ou no valor calculado do limite de detecção que foi de $0,03 \mathrm{mg}$ $\mathrm{kg}^{-1}$. Por isso, qualquer conclusão a respeito destes valores de $\mathrm{Cd}$ extraído pelos extratores convencionais apresentado por estes solos estaria passível de erros. Para os demais solos os valores de Cd extraído obtidos são válidos uma vez que apresentam-se acima do limite de detecção calculado. Possivelmente o maior teor de argila poderia também estar dificultando a extração do Cd pela menor quantidade de superfície exposta razão pela qual a solução de Mehlich 3 não tenha mostrado eficiência. Outro fato seria o pH mais elevado, que estaria influenciando na extração do $\mathrm{Cd}$, uma vez que a medida que o $\mathrm{pH}$ se eleva o 
Cd por ser um cátion torna-se menos solúvel e portanto menos disponível (Barrow et al., 1989). O que não estaria de acordo com Monterroso et al. (1999) que obteve melhores resultados de extração de Cd utilizando-se a solução de Mehlich 3 comparada com a solução de DTPA-TEA pH 7,3 devido principalmente à acidez do reagente Mehlich 3 sendo ela responsável por um alto poder de extração particularmente em amostras alcalinas. Segundo Xiu et al. (1991) a extração utilizando-se a solução de Mehlich 3 pode ser preferida nas análises de rotina em laboratórios graças ao pequeno período de agitação de cinco minutos quando comparado com outros extratores.

Quando utilizada a solução extratora DTPA-TEA pH 7,3 os solos apresentaram um teor extraído variando de 0 a $0,46 \mathrm{mg} \mathrm{kg}^{-1}$ de cádmio nas amostras estudadas. O LVdf-1 foi a única amostra que embora tenha apresentado maior valor de Cd total, teve um teor de Cd extraído pelo DTPATEA pH 7,3 abaixo do limite de detecção calculado que foi de $0,03 \mathrm{mg} \mathrm{kg}^{-1}$. Possivelmente por ser um solo que apresentava o maior teor de argila contribuindo na retenção de Cd em virtude da maior superfície exposta, além do $\mathrm{pH}$ mais elevado que influenciaria na extração do elemento tornando-o menos disponível por ser um cátion metálico, e também devido ao maior teor de ferro cristalino que poderia estar possibilitando uma adsorção específica do $\mathrm{Cd}$ formando complexos entre a superfície da fração com o metal (McBride, 1989).

No caso da solução extratora $\mathrm{CaCl}_{2}$,, $01 \mathrm{~mol} \mathrm{~L}^{-1}$ os solos apresentaram um teor em torno de $0,07 \mathrm{mg} \mathrm{kg}^{-1}$ do elemento nas amostras naturais. Não se observou variação nos dados possivelmente porque este elemento em condições naturais não se encontra em quantidade considerável em solução ou mesmo fracamente adsorvido no solo ou porque a concentração da solução extratora utilizada poderia não ter sido suficiente para extrair o $\mathrm{Cd}$ destes solos. Em estudo feito por Krishnamurti et al. (2000), a extração de Cd utilizando uma solução de $0,05 \mathrm{~mol} \mathrm{~L}^{-1}$ de $\mathrm{CaCl}_{2}$ foi maior comparada com a extração pelo emprego de uma solução $0,01 \mathrm{~mol} \mathrm{~L}^{-1}$ de $\mathrm{CaCl}_{2}$. Além disso, o uso do $\mathrm{CaCl}_{2}$ foi defendido na Europa e Nova Zelândia baseado na suposição de que o Cd 
estaria na maior parte ligado a minerais e o $\mathrm{Ca}$ da solução de $\mathrm{CaCl}_{2}$ facilitaria a troca.

Pelo teste de Tukey (anexos) quando comparada as extrações feitas pelo emprego da solução Mehlich 3, do DTPA-TEA pH 7,3 e do $\mathrm{CaCl}_{2}$ 0,01 mol L-1 foi visto que o DTPA-TEA pH 7,3 mostrou diferença significativa entre os tratamentos sendo mais eficiente para extrair o $\mathrm{Cd}$ das amostras dos solos naturais com exceção do LVAw. Isto concorda com King \& Hajjar (1990) na medida em que estes autores estudando o efeito residual do lodo de esgoto sobre a concentração de metais pesados em plantas de tabaco e amendoim, e usando um podzólico de textura média obtiveram os melhores resultados de extração de Cd do solo com DTPA-TEA pH 7,3 quando comparado ao Mehlich 3. Resultados parecidos foram obtidos por Mulchi et al. (1991) estudando correlações entre os teores de Cd extraído por DTPA-TEA pH 7,3 e Mehlich 1 e 3 de um solo onde havia sido adicionado lodo de esgoto, e os absorvidos por plantas de tabaco, observando melhores correlações de extração para o Cd por DTPA-TEA pH 7,3. Isto estaria de acordo com Roca et al. (1991) que comenta ser o DTPA-TEA pH 7,3 um indicador da disponibilidade de metais em solos com adicional vantagem de extrair simultaneamente um número de elementos essenciais pela planta bem como de metais pesados. Xiu et al. (1991) admite ser o DTPA-TEA pH 7,3 o melhor extrator de metais embora apresente, quando comparado com o extrator Mehlich 3, a desvantagem do tempo de agitação de duas horas enquanto o do Mehlich 3 são cinco minutos. Ao contrário, Miner et al. (1997) obteve maiores valores de extração de Cd quando utilizou a solução de Mehlich 3 quando comparada com o extrator DTPA-TEA pH 7,3. Krishnamurti et al. (2000) usando diferentes extratores para avaliar o Cd disponível em solos verificou ser a extração por DTPA-TEA pH 7,3 maior do que a obtida por $\mathrm{CaCl}_{2}$ não sendo este fato surpreendente devido ao modo de ação de cada extrator.

Ainda pelo teste de Tukey (anexos) não foi observada diferença significativa entre as extrações de Cd nas diferentes amostras dos solos naturais e entre as 
diferentes amostras dos solos naturais e os tratamentos indicando que houve diferença significativa entre os tratamentos sendo que apenas a extração pelo DTPA pH 7,3 diferiu dentre eles.

\subsubsection{Análises de regressão simples entre os extratores convencionais e as variáveis independentes para os quinze solos estudados}

Para o extrator DTPA-TEA pH 7,3, com auxílio da análise de regressão simples entre os três extratores convencionais (Mehlich 3, DTPA-TEA pH 7,3 e $\mathrm{CaCl}_{2}$ 0,01 $\mathrm{mol} \mathrm{L}^{-1}$ ) e os atributos do solo (anexos), foi possível identificar o teor de argila $(r=-0,73)$ como o atributo que apresentou maior correlação negativa significativa com a extração do $\mathrm{Cd}$, seguido pelos teores de óxidos de ferro $(r=-0,65)$ e alumínio $(r=-0,64)$, extraíveis com ditionito, e pelo $\mathrm{pH}$ em $\mathrm{KCl} 1$ $\mathrm{mol} \mathrm{L}^{-1}(r=-0,47)$. Assim, os solos que apresentaram menores teores de argila, de ferro e alumínio cristalinos e menores valores de $\mathrm{pH}$ mostraram uma maior extração de Cd pelo extrator DTPA-TEA pH 7,3. Ao contrário, não foi possível identificar nenhum atributo que tenha se relacionado com o extrator Mehlich $3 \mathrm{e}$ com a solução de $\mathrm{CaCl}_{2} \quad 0,01 \mathrm{~mol} \mathrm{~L}^{-1}$ (anexos). Para esses extratores convencionais os valores dos coeficientes de correlação $r$ encontrados na análise de regressão simples foram muito baixos, o que não era esperado pois acreditava-se, pelo menos para o extrator Mehlich 3 , que dentre as variáveis independentes escolhidas no estudo alguma apresentaria correlação significativa com a extração de Cd por estes extratores já que foram escolhidas amostras com uma faixa ampla de variação dos atributos que deveriam em algum grau influenciar na extração do $\mathrm{Cd}$. Já para o $\mathrm{CaCl}_{2} 0,01 \mathrm{~mol} \mathrm{~L}^{-1}$ a baixa correlação não significativa pode possivelmente ser justificada porque este elemento, em condições naturais, poderia não se encontrar em quantidade considerável em solução ou mesmo estar fracamente adsorvido no solo. 
A correlação negativa significativa entre o teor de argila e o DTPA-TEA pH 7,3 mostrou que a superfície exposta da fração mineral constituída principalmente por minerais de argila do tipo 1:1, por se tratar de solos muito intemperizados, teve influência no processo de extração do Cd. Assim, solos que apresentam maior teor de argila e, consequentemente, maior superfície exposta e possivelmente balanço de cargas variáveis negativo mostraram uma maior capacidade de retenção do Cd e portanto, menor chance de extração do elemento, concordando com o estabelecido por Kort et al (1976).

A correlação negativa significativa entre o teor de ferro e alumínio extraíveis com ditionito nesses solos mostram de maneira indireta a importância das formas cristalinas de ferro e alumínio na adsorção do elemento neste estudo, concordando com McBride (1989) que verificou a alta especificidade dos óxidos por certos metais pesados, entre eles o $\mathrm{Cd}$.

Foi verificada correlação negativa significativa entre o Cd extraído por DTPA-TEA pH 7,3 com o pH em KCl $1 \mathrm{~mol} \mathrm{~L}^{-1}$. Notou-se que a medida que 0 $\mathrm{pH}$ diminuiu, pode ter ocorrido maior solubilização do elemento facilitando a extração do mesmo, resultado que corrobora os de Garcia \& Miragaya (1978) e os de King (1988) que observaram um aumento da adsorção de Cd com a elevação do pH ressaltando o que foi observado por Barrow et el., 1989.

A ausência de correlação entre o extrator DTPA-TEA pH 7,3 e o teor de carbono orgânico e entre a CTC dos solos foi de certa forma uma surpresa uma vez que, na camada superficial dos solos normalmente ocorre um balanço de cargas negativas em razão do alto teor de carbono orgânico, o que resulta em uma elevada CTC. Esta ausência de correlação vem de encontro com as observações de Singh (1979) e Petruzzelli et al. (1985), que verificaram que solos que apresentam maior teor de matéria orgânica e consequente CTC mostraram uma maior adsorção de cádmio, principalmente em superfície, pois é nela que se encontram os maiores valores para estes atributos. Não concorda também com os resultados de Dias et al. (2001) que mostraram que a CTC foi 
o atributo que teve o maior efeito sobre a adsorção de Cd para um Nitossolo Vermelho eutroférrico e dois latossolos do estado de São Paulo.

A análise de regressão linear simples também não mostrou correlação significativa entre o extrator DTPA-TEA pH 7,3 e o teor de $\mathrm{Cd}$ total das amostras de solos. Este é um resultado que merece ser ressaltado pois, como também aconteceu com os outros dois extratores, o valor de Cd total não deve se relacionar com a sua disponibilidade para o meio ambiente.

\subsubsection{Análise de regressão múltipla entre os extratores convencionais e as variáveis independentes dos solos naturais}

Considerando-se a natureza heterogênea dos solos estudados e a possibilidade de vários de seus atributos estarem associados ao mecanismo de extração de cádmio, decidiu-se realizar uma análise de regressão múltipla. Com o auxílio dessa análise, foi possível verificar o efeito conjunto dos atributos dos solos sobre a extração de Cd.

A análise de regressão múltipla (anexos) foi importante pois mostrou que o atributo que melhor explicou a extração de Cd (53\%) pelo extrator DTPA-TEA $\mathrm{pH} 7,3$ foi o teor de argila dos solos. A equação que melhor se ajustou foi:

DTPA-TEA pH 7,3 = 0,3489 - 0,00046 argila 


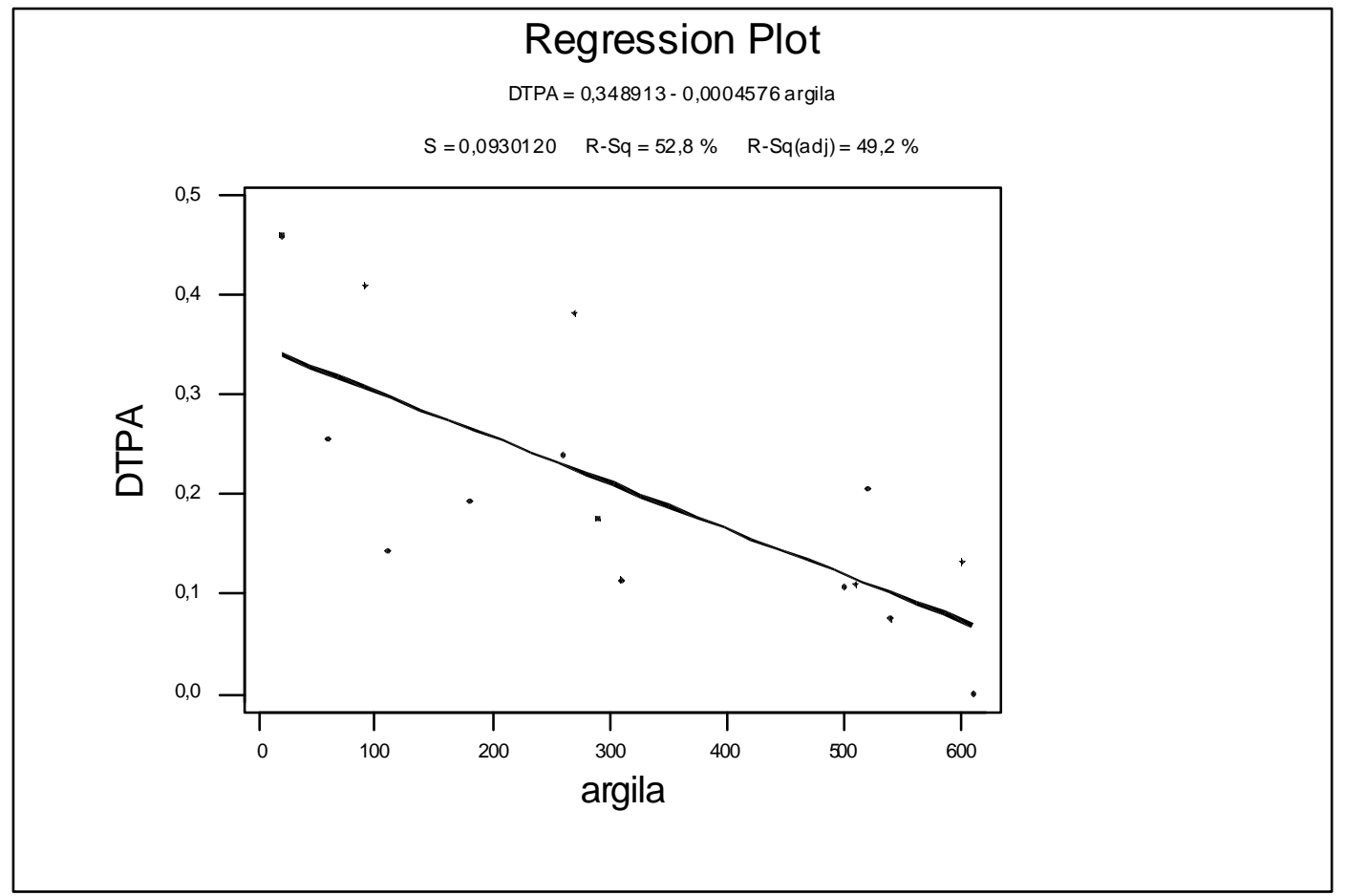

Figura 1 - Regressão linear negativa significativa entre o DTPA e o teor de argila dos solos

Estes resultados encontram apoio na constatação de Kort et al. (1976) que verificou que a adsorção aumentava com a superfície específica do solo. Entretanto, não encontram nas observações de Dias (2001) que obteve um valor de constante de afinidade na equação de Langmuir maior onde havia menor teor de argila, devendo apresentar, portanto, menor chance de extração de Cd.

\subsection{Potencialidade de extração de Cd por ácidos orgânicos}

\subsubsection{Na concentração da solução do solo}

Ácidos orgânicos de baixo peso molecular, como o acético, cítrico e oxálico geralmente estão presentes nos exsudatos de raízes, sendo muito eficientes na 
solubilização dos metais presentes no solo (Krishnamurti et al., 1997). Assim, conseguindo-se identificar a composição química desses exsudatos, eles podem vir a ser usados como extratores naturais podendo-se estimar com precisão as quantidades biodisponíveis totais dos metais presentes no solo e correlacioná-los com aqueles contidos na planta. A composição química dos exsudatos de raízes é específica para cada espécie e difere quanto a solubilização dos metais para cada espécie vegetal. Conhecendo-se a composição química para determinada espécie pode-se formular exsudatos sintéticos de uso rotineiro em laboratório .

No intuito de se obterem dados preliminares para nossas condições, extraiu-se o cádmio com os três ácidos que se apresentaram em quantidade relativa mais elevada que outros na solução do solo e perto da zona radicular (Wolt, 1994). Os resultados obtidos encontram-se na tabela 6.

Tabela 6. Extração de Cd das amostras dos solos naturais por soluções de ácidos orgânicos. Média de três repetições.

\begin{tabular}{|c|c|c|c|c|}
\hline solos & Acético & $\begin{array}{c}\text { Cítrico } \\
\quad \mathrm{Cd} \\
\mathrm{mg} \mathrm{kg}^{-1}\end{array}$ & Oxálico & Cd Total \\
\hline LVj & 0,04 & 0,04 & 0,04 & 0,10 \\
\hline LVef & 0,04 & 0,04 & 0,04 & 0,30 \\
\hline LAw & 0,04 & 0,04 & 0,03 & 0,00 \\
\hline PVAe & 0,03 & 0,04 & 0,04 & 0,04 \\
\hline PVAd-1 & 0,03 & 0,04 & 0,04 & 0,71 \\
\hline PVAd-2 & 0,04 & 0,04 & 0,04 & 1,04 \\
\hline LVd & 0,04 & 0,04 & 0,03 & 1,58 \\
\hline LVdf-1 & 0,03 & 0,04 & 0,04 & 2,01 \\
\hline LVdf-2 & 0,04 & 0,04 & 0,04 & 2,23 \\
\hline LVAd-1 & 0,04 & 0,04 & 0,03 & 0,96 \\
\hline LVAd-2 & 0,06 & 0,04 & 0,03 & 1,60 \\
\hline LVAw & 0,04 & 0,04 & 0,04 & 1,44 \\
\hline NVef & 0,04 & 0,04 & 0,04 & 1,88 \\
\hline RQo & 0,04 & 0,04 & 0,04 & 1,00 \\
\hline SXd & 0,04 & 0,04 & 0,03 & 1,48 \\
\hline
\end{tabular}


Para os solos naturais a variação no teor de Cd removido pelos diferentes extratores, foi respectivamente, de 0,03 a 0,06; de 0,04 e de 0,03 a 0,04 $\mathrm{mg} \mathrm{kg}^{-1}$ para os ácidos acético, cítrico e oxálico. A variação quase nula observada se deve possivelmente à baixa concentração das soluções de ácidos orgânicos utilizadas e ao baixo teor de $\mathrm{Cd}$ total nestes solos e ao limite de detecção do elemento nas soluções que provavelmente esteja perto de 0,03 como já determinado anteriormente para os outros três extratores. A mais alta extração aconteceu com o uso da solução de ácido acético talvez por apresentar uma concentração mais elevada que os outros dois. Observou-se que os ácidos orgânicos extraíram relativamente quantidades menores de $\mathrm{Cd}$ dos solos quando comparadas com as quantidades extraídas pelo emprego dos extratores químicos DTPA-TEA pH 7,3 e Mehlich 3. Esperava-se uma extração maior em virtude da maior possibilidade de solubilização do metal pelos ácidos empregados (Krishnamurti et al. 1997). De acordo com Godo e Reisenauer (1980) e Merckx et al. (1986) como a concentração de metais na solução do solo é muito baixa, a sua solubilização quando presentes na fase sólida por exsudatos de raízes na região da rizosfera não deve ser desprezada. Assim, o uso destes ácidos não deve ser descartado como possibilidade de utilização futura e, mais estudos quanto a concentração, relação solo:solução e tempo de contato adequados para diferentes tipos de solos devem ser desenvolvidos. A análise estatística não foi empregada em virtude de os valores se encontrarem muito próximos do limite de detecção do aparelho.

\subsection{Extração de Cd em solos contaminados}

$\mathrm{Na}$ tabela 7 encontram-se os resultados da extração de $\mathrm{Cd}$ pelo uso dos três extratores convencionais e orgânicos para as amostras de solos de regiões com alguma contaminação. 
Tabela 7. Extração de $\mathrm{Cd}$ das amostras dos solos contaminados por soluções de extratores convencionais e orgânicos

\begin{tabular}{cccccccc}
\hline & Mehlich 3 & DTPA & $\mathrm{CaCl}_{2}$ & Acético & Cítrico & Oxálico & Cd Total \\
\hline Amostra & -- & $\begin{array}{c}\text { Cd } \\
\text { mg kg }\end{array}$ & Cd \\
\hline & & & & \\
AM1 & 43,25 & 21,03 & 0,07 & 1,75 & 0,36 & 0,23 & 114,50 \\
AM2 & 0,07 & 0,11 & 0,07 & 0,04 & 0,04 & 0,04 & 1,74 \\
AM3 & 0,40 & 0,06 & 0,07 & 0,04 & 0,04 & 0,03 & 1,51 \\
AM4 & 0,84 & 0,15 & 0,07 & 0,04 & 0,04 & 0,04 & 0,67 \\
AM5 & 0,28 & 0,08 & 0,07 & 0,03 & 0,05 & 0,03 & 0,37 \\
AM6 & 0,14 & 0,25 & 0,07 & 0,04 & 0,05 & 0,04 & 0,50 \\
AM7 & 0,41 & 0,10 & 0,07 & 0,04 & 0,04 & 0,03 & 0,66 \\
AM8 & 0,74 & 0,02 & 0,07 & 0,04 & 0,04 & 0,03 & 0,20 \\
\hline
\end{tabular}

Foi observado que o teor de Cd usando a solução extratora Mehlich 3 variou de 0,07 a 43,25 com destaque para a amostra 1 que era proveniente de um solo de área contaminada pela indústria Zincomatic em Guararema, SP e que apresentava maior quantidade de Cd total extraído por digestão com ácido nítrico em microndas. $\mathrm{O}$ valor de $\mathrm{Cd}$ extraído da amostra 1 mostrou que a área de onde a amostra foi retirada encontra-se poluída uma vez que o valor obtido apresentou-se fora dos padrões de nível crítico estabelecidos pela USEPA (20 $\mathrm{mg} \mathrm{kg}^{-1}$ ) e pela Diretriz da Comunidade Européia (1-3 $\mathrm{mg} \mathrm{kg}^{-1}$ ) para este elemento. O Mehlich 3 mostrou-se mais eficiente para extrair o $\mathrm{Cd}$ das amostras contaminadas quando comparado ao DTPA-TEA pH 7,3, diferentemente das amostras naturais. Possivelmente o $\mathrm{Cd}$ presente nestas amostras não estivesse ligado à matéria orgânica, pois o DTPA-TEApH 7,3 tem como característica a extração de elementos ligados a ela. Assim, nestes solos o Cd poderia estar mais ligado à fração mineral.

No caso do uso da solução extratora DTPA-TEA pH 7,3 o teor encontrado de $\mathrm{Cd}$ variou de 0,02 a 21,03 $\mathrm{mg} \mathrm{kg}^{-1}$ destacando-se a amostra 1, possivelmente graças à sua maior quantidade de $\mathrm{Cd}$ total (tabela 7 ).

Para $\circ \mathrm{CaCl}_{2}$ 0,01 $\mathrm{mol} \mathrm{L}^{-1}$ os teores estiveram próximos de $0,07 \mathrm{mg} \mathrm{kg}^{-1}$, mesmo para a amostra 1 tida como contaminada. Observou-se que mesmo 
para as amostras contaminadas $\circ \mathrm{CaCl}_{2} 0,01 \mathrm{~mol} \mathrm{~L}^{-1}$ também não se mostrou eficiente para a extração de $\mathrm{Cd}$.

Os ácidos orgânicos foram utilizados para, de maneira exploratória, verificar a potencialidade de extração de Cd dos solos estudados. É importante dizer que não se procurou comparar a extração de cádmio pelo uso de extratores convencionais com o uso de extratores de soluções de ácidos orgânicos e sim, apenas verificar se as soluções de ácidos orgânicos de baixo peso molecular mostram alguma potencialidade de extração do $\mathrm{Cd}$ nos diferentes solos utilizados. Para as condições estudadas não se notou qualquer destaque para nenhum dos três ácidos.

A tabela 7 mostra os teores de $\mathrm{Cd}$ extraídos das amostras de solos supostamente contaminados pelo uso da solução de ácido acético, ácido cítrico e ácido oxálico. Para as amostras de solos contaminadas os teores de $\mathrm{Cd}$ extraído variaram de 0,03 a 1,75;0,04 a 0,36 e de 0,03 a $0,23 \mathrm{mg} \mathrm{kg}^{-1}$, respectivamente para estes três ácidos, cabendo destacar a extração de $\mathrm{Cd}$ pela solução de ácido acético da amostra 1 que continha maior teor de Cd total.

Possivelmente adotando-se uma maior concentração das soluções de ácidos orgânicos de baixo peso molecular e maior tempo de reação haveria uma maior liberação de $\mathrm{Cd}$ dos solos de acordo com os estudos de Krishnamurti et al. (1997), utilizando uma relação solo:solução de 1:10 e soluções de ácidos orgânicos de baixo peso molecular com uma concentração de $10^{-2} \mathrm{~mol} \mathrm{~L}^{-1}$ por um período de até $8 \mathrm{~h}$. Esse mesmo autor constatou que o Cd liberado dos solos foi influenciado pelos ácidos orgânicos até o tempo de $2 \mathrm{~h}$ de reação sugerindo que após esse período ocorre uma degradação microbiana dos ácidos e o $\mathrm{Cd}$ presente como $\mathrm{Cd}^{2+}$ na solução do solo sofre uma readsorção pela superfície das partículas dos solos. Embora neste estudo nada se tenha encontrado de evidência da possibilidade do uso destes ácidos, parece que pelas observações da literatura ainda valeria a pena trabalhar no assunto com maior profundidade. 


\section{CONCLUSÕES}

Os resultados obtidos neste trabalho permitem concluir que:

- O Cd extraído pelo extrator convencional DTPA-TEA pH 7,3 apresentou correlação linear simples negativa com argila, ferro livre e pH em $\mathrm{KCl} 1$ mol L ${ }^{-1}$ e na regressão múltipla o teor de argila dos solos naturais foi a variável que mais influenciou a extração e negativamente.

- Pode-se dizer que o DTPA-TEA pH 7,3 apresentou maior capacidade de extração para o Cd das amostras dos solos naturais do que o Mehlich 3. $\mathrm{O}$ uso da solução de $\mathrm{CaCl}_{2}$ 0,01 mol L-1 não foi eficiente para extrair e diferenciar $\mathrm{Cd}$ dos solos estudados.

- As soluções de ácidos orgânicos na concentração, relação solo:solução e tempo de contato estudados extraíram pequena quantidade de $\mathrm{Cd}$ dos solos naturais, com pequeno destaque para o ácido acético. 
ANEXOS 


\section{Análise de Regressão Simples}

\section{Mehlich 3 e pH KCI}

The regression equation is

Mehlich $3=0.170-0.0201 \mathrm{pH} \mathrm{KCl}$

$\begin{array}{lcccc}\text { Predictor } & \text { Coef } & \text { StDev } & \text { T } & \text { P } \\ \text { Constant } & 0,16993 & 0,09938 & 1,71 & 0,111 \\ \text { pH KCl } & -0,02015 & 0,02009 & -1 & 0,334\end{array}$

$S=0.06247 \quad R-S q=7.2 \% \quad R-S q(\operatorname{adj})=0.0 \%$

Analysis of Variance

$\begin{array}{lccccc}\text { Source } & \text { DF } & \text { SS } & \text { MS } & \text { F } & \text { P } \\ \text { Regression } & 1 & 0,003923 & 0,003923 & 1,01 & 0,334 \\ \text { Error } & 13 & 0,050728 & 0,003902 & & \\ \text { Total } & 14 & 0,054652 & & & \end{array}$

Unusual Observations

Obs $\mathrm{pH} \mathrm{KCl}$ Mehlich Fit StDev Fit Residual St Resid

$\begin{array}{lllllll}12 & 4.10 & 0.2700 & 0.0873 & 0.0225 & 0.1827 & 3.13 R\end{array}$

\section{Mehlich 3 e C}

The regression equation is

Mehlich $3=0.0461+0.00189 \mathrm{C}$

$\begin{array}{lcccc}\text { Predictor } & \text { Coef } & \text { StDev } & \text { T } & \text { P } \\ \text { Constant } & 0,04609 & 0,03683 & 1,25 & 0,233 \\ \text { C } & 0,001894 & 0,00245 & 0,77 & 0,453\end{array}$

$S=0.06340 \quad R-S q=4.4 \% \quad R-S q(a d j)=0.0 \%$

Analysis of Variance

$\begin{array}{lccccc}\text { Source } & \text { DF } & \text { SS } & \text { MS } & \text { F } & \text { P } \\ \text { Regression } & 1 & 0,002404 & 0,002404 & 0,6 & 0,453 \\ \text { Error } & 13 & 0,052248 & 0,004019 & & \\ \text { Total } & 14 & 0,054652 & & & \end{array}$

Unusual Observations

Obs C Mehlich

$\begin{array}{lllllll}12 & 10.0 & 0.2700 & 0.0650 & 0.0184 & 0.2050 & 3.38 \mathrm{R}\end{array}$




\section{Mehlich 3 e CTC}

The regression equation is

Mehlich $3=0.0670+0.000072$ CTC

$\begin{array}{lcccc}\text { Predictor } & \text { Coef } & \text { StDev } & \text { T } & \text { P } \\ \text { Constant } & 0,06698 & 0,03309 & 2,02 & 0,064 \\ \text { CTC } & 7,22 E-05 & 0,000446 & 0,16 & 0,874\end{array}$

$S=0.06477 \quad R-S q=0.2 \% \quad R-S q(\operatorname{adj})=0.0 \%$

Analysis of Variance

$\begin{array}{lccccc}\text { Source } & \text { DF } & \text { SS } & \text { MS } & \text { F } & \text { P } \\ \text { Regression } & 1 & 0,00011 & 0,00011 & 0,03 & 0,874 \\ \text { Error } & 13 & 0,054542 & 0,004196 & & \\ \text { Total } & 14 & 0,054652 & & & \end{array}$

Unusual Observations

Obs CTC Mehlich Fit StDev Fit Residual St Resid

$\begin{array}{lllllll}2 & 150 & 0.0730 & 0.0778 & 0.0416 & -0.0048 & -0.10 X\end{array}$

$\begin{array}{lllllll}12 & 37 & 0.2700 & 0.0697 & 0.0206 & 0.2003 & 3.26 \mathrm{R}\end{array}$

\section{Mehlich 3 e argila}

The regression equation is

Mehlich $3=0.0790-0.000023$ argila

$\begin{array}{lcccc}\text { Predictor } & \text { Coef } & \text { StDev } & \text { T } & \text { P } \\ \text { Constant } & 0,07901 & 0,03182 & 2,48 & 0,027 \\ \text { argila } & -2,3 \mathrm{E}-05 & 8,34 \mathrm{E}-05 & -0,27 & 0,789\end{array}$

$\mathrm{S}=0.06465 \quad \mathrm{R}-\mathrm{Sq}=0.6 \% \quad \mathrm{R}-\mathrm{Sq}(\mathrm{adj})=0.0 \%$

Analysis of Variance

$\begin{array}{lccccc}\text { Source } & \text { DF } & \text { SS } & \text { MS } & F & P \\ \text { Regression } & 1 & 0,000313 & 0,000313 & 0,07 & 0,789 \\ \text { Error } & 13 & 0,054339 & 0,00418 & & \\ \text { Total } & 14 & 0,054652 & & & \end{array}$

Unusual Observations Obs argila Mehlich

$\begin{array}{lllllll}12 & 180 & 0.2700 & 0.0749 & 0.0206 & 0.1951 & 3.18 \mathrm{R}\end{array}$




\section{Mehlich 3 e ferro ditionito}

The regression equation is

Mehlich $3=0.0814-0.00223 \mathrm{Fe}$ (ditionito)

$\begin{array}{lcccc}\text { Predictor } & \text { Coef } & \text { StDev } & \text { T } & \text { P } \\ \text { Constant } & 0,08137 & 0,02335 & 3,48 & 0,004 \\ \text { Fe(ditio } & -0,00223 & 0,003759 & -0,59 & 0,564\end{array}$

$S=0.06398 \quad R-S q=2.6 \% \quad R-S q(\operatorname{adj})=0.0 \%$

Analysis of Variance

$\begin{array}{lccccc}\text { Source } & \text { DF } & \text { SS } & \text { MS } & \text { F } & \text { P } \\ \text { Regression } & 1 & 0,001434 & 0,001434 & 0,35 & 0,564 \\ \text { Error } & 13 & 0,053218 & 0,004094 & & \\ \text { Total } & 14 & 0,054652 & & & \end{array}$

Unusual Observations

Obs Fe(ditio Mehlich Fit StDev Fit Residual St Resid

$\begin{array}{lllllll}12 & 0.6 & 0.2700 & 0.0800 & 0.0217 & 0.1900 & 3.16 \mathrm{R}\end{array}$

\section{Mehlich 3 e Cd total}

The regression equation is

Mehlich $3=0.0626+0.0083 \mathrm{Cd}$ total

$\begin{array}{lcccc}\text { Predictor } & \text { Coef } & \text { StDev } & \text { T } & \text { P } \\ \text { Constant } & 0,06257 & 0,03048 & 2,05 & 0,061 \\ \text { Cd total } & 0,00827 & 0,02339 & 0,35 & 0,729\end{array}$

$S=0.06453 \quad R-S q=1.0 \% \quad R-S q(\operatorname{adj})=0.0 \%$

Analysis of Variance

$\begin{array}{lccccc}\text { Source } & \text { DF } & \text { SS } & \text { MS } & \text { F } & \text { P } \\ \text { Regression } & 1 & 0,000521 & 0,000521 & 0,13 & 0,729 \\ \text { Error } & 13 & 0,054131 & 0,004164 & & \\ \text { Total } & 14 & 0,054652 & & & \end{array}$

Unusual Observations

Obs Cd total Mehlich Fit StDev Fit Residual St Resid

$\begin{array}{lllllll}12 & 1.44 & 0.2700 & 0.0745 & 0.0185 & 0.1955 & 3.16 \mathrm{R}\end{array}$




\section{Análise de Regressão Simples}

\section{DTPA e $\mathrm{pH} \mathrm{KCI}$}

The regression equation is

DTPA $=0.557-0.0732 \mathrm{pH} \mathrm{KCl}$

$\begin{array}{lcccc}\text { Predictor } & \text { Coef } & \text { StDev } & \text { T } & \text { P } \\ \text { Constant } & 0,5573 & 0,1905 & 2,93 & 0,012 \\ \text { pH KCl } & -0,07316 & 0,03853 & -1,9 & 0,08\end{array}$

$S=0.1198 \quad R-S q=21.7 \% \quad R-S q(\operatorname{adj})=15.7 \%$

Analysis of Variance

$\begin{array}{lccccc}\text { Source } & \text { DF } & \text { SS } & \text { MS } & \text { F } & \text { P } \\ \text { Regressior } & 1 & 0,05172 & 0,05172 & 3,61 & 0,08 \\ \text { Error } & 13 & 0,18648 & 0,01434 & & \\ \text { Total } & 14 & 0,2382 & & & \end{array}$

\section{DTPA e C}

The regression equation is

DTPA $=0.265-0.00478 \mathrm{C}$

$\begin{array}{lcccc}\text { Predictor } & \text { Coef } & \text { StDev } & \text { T } & \text { P } \\ \text { Constant } & 0,26476 & 0,07606 & 3,48 & 0,004 \\ \text { C } & -0,00478 & 0,005059 & -0,95 & 0,362\end{array}$

$S=0.1309 \quad R-S q=6.4 \% \quad R-S q(\operatorname{adj})=0.0 \%$

Analysis of Variance

$\begin{array}{lccccc}\text { Source } & \text { DF } & \text { SS } & \text { MS } & \text { F } & \text { P } \\ \text { Regressior } & 1 & 0,01533 & 0,01533 & 0,89 & 0,362 \\ \text { Error } & 13 & 0,22287 & 0,01714 & & \\ \text { Total } & 14 & 0,2382 & & & \end{array}$




\section{DTPA e CTC}

The regression equation is DTPA $=0.275-0.00116$ CTC

$\begin{array}{lcccc}\text { Predictor } & \text { Coef } & \text { StDev } & \text { T } & \text { P } \\ \text { Constant } & 0,27492 & 0,06486 & 4,24 & 0,001 \\ \text { CTC } & -0,00116 & 0,000874 & -1,33 & 0,206\end{array}$

$S=0.1270 \quad R-S q=12.0 \% \quad R-S q(\operatorname{adj})=5.3 \%$

Analysis of Variance

\begin{tabular}{|c|c|c|c|c|c|}
\hline Source & DF & SS & MS & $\mathrm{F}$ & $\mathrm{P}$ \\
\hline Regressior & 1 & 0,02863 & 0,02863 & 1,78 & 0,206 \\
\hline Error & 13 & 0,20958 & 0,01612 & & \\
\hline Total & 14 & 0,2382 & & & \\
\hline \multicolumn{6}{|c|}{ Unusual Observations } \\
\hline CTC & DTPA & Fit & StDev Fit & Residual & St Resid \\
\hline 150 & 0.1100 & 0.1007 & 0.0816 & 0.0093 & $0.10 x$ \\
\hline
\end{tabular}

\section{DTPA e argila}

The regression equation is

DTPA $=0.349-0.000458$ argila

$\begin{array}{lcccc}\text { Predictor } & \text { Coef } & \text { StDev } & \text { T } & P \\ \text { Constant } & 0,34891 & 0,04578 & 7,62 & 0 \\ \text { argila } & -0,00046 & 0,00012 & -3,81 & 0,002\end{array}$

$S=0.09301 \quad R-S q=52.8 \% \quad R-S q(a d j)=49.2 \%$

Analysis of Variance

$\begin{array}{lccccc}\text { Source } & \text { DF } & \text { SS } & \text { MS } & \text { F } & \text { P } \\ \text { Regressior } & 1 & 0,12574 & 0,12574 & 14,53 & 0,002 \\ \text { Error } & 13 & 0,11247 & 0,00865 & & \\ \text { Total } & 14 & 0,2382 & & & \end{array}$




\section{DTPA e ferro ditionito}

The regression equation is

DTPA $=0.283-0.0188 \mathrm{Fe}$ (ditionito)

Predictor Coef StDev $\quad$ T $\quad$ P

$\begin{array}{lllll}\text { Constant } & 0,28272 & 0,03737 & 7,57 & 0\end{array}$

Fe(ditio $\quad-0,01876 \quad 0,006015 \quad-3,12 \quad 0,008$

$S=0.1024 \quad R-S q=42.8 \% \quad R-S q(\operatorname{adj})=38.4 \%$

Analysis of Variance

$\begin{array}{lccccc}\text { Source } & \text { DF } & \text { SS } & \text { MS } & \text { F } & \text { P } \\ \text { Regressior } & 1 & 0,10196 & 0,10196 & 9,73 & 0,008 \\ \text { Error } & 13 & 0,13624 & 0,01048 & & \\ \text { Total } & 14 & 0,2382 & & & \end{array}$

\section{DTPA e Cd total}

The regression equation is

DTPA $=0.278-0.0709 \mathrm{Cd}$ total

Predictor Coef StDev T P

$\begin{array}{lllll}\text { Constant } & 0.27766 & 0.05859 & 4.74 & 0.000\end{array}$

$\begin{array}{lllll}\text { Cd total } & -0.07086 & 0.04496 & -1.58 & 0.139\end{array}$

$S=0.1240 \quad R-S q=16.0 \% \quad R-S q(\operatorname{adj})=9.6 \%$

Analysis of Variance

\begin{tabular}{lrcccc} 
Source & DF & SS & MS & F & \multicolumn{2}{c}{$P$} \\
Regression & 1 & 0.03822 & 0.03822 & 2.48 & 0.139 \\
Error & 13 & 0.19999 & 0.01538 & &
\end{tabular}

Unusual Observations

Obs Cd total DTPA Fit StDev Fit Residual St Resid

$\begin{array}{lllllll}14 & 1.00 & 0.4600 & 0.2068 & 0.0323 & 0.2532 & 2.11 \mathrm{R}\end{array}$




\section{Análise de Regressão Simples}

\section{$\mathrm{CaCl}_{2}$ e $\mathrm{pH} \mathrm{KCl}$}

The regression equation is

$\mathrm{CaCl}_{2}=0.0697-0.000023 \mathrm{pH} \mathrm{KCl}$

$\begin{array}{lcccc}\text { Predictor } & \text { Coef } & \text { StDev } & \text { T } & P \\ \text { Constant } & 0,069711 & 0,000837 & 83,33 & 0 \\ \text { pH KCl } & -2,3 E-05 & 0,000169 & -0,13 & 0,895\end{array}$

$S=0.0005259 \quad R-S q=0.1 \% \quad R-S q(\operatorname{adj})=0.0 \%$

Analysis of Variance

$\begin{array}{lccccc}\text { Source } & \text { DF } & \text { SS } & \text { MS } & F & P \\ \text { Regression } & 1 & 5,01 \mathrm{E}-04 & 5,01 \mathrm{E}-04 & 0,02 & 0,895 \\ \text { Error } & 13 & 3,59 \mathrm{E}-01 & 2,77 \mathrm{E}-02 & & \\ \text { Total } & 14 & 3,60 \mathrm{E}-01 & & & \end{array}$

\section{$\underline{\mathrm{CaCl}_{2} \text { e C }}$}

The regression equation is

$\mathrm{CaCl}_{2}=0.0695+0.000004 \mathrm{C}$

$\begin{array}{lcccc}\text { Predictor } & \text { Coef } & \text { StDev } & T & P \\ \text { Constant } & 0,069544 & 0,000305 & 227,87 & 0 \\ \text { C } & 4,18 E-06 & 2,03 E-05 & 0,21 & 0,84\end{array}$

$S=0.0005254 \quad R-S q=0.3 \% \quad R-S q(\operatorname{adj})=0.0 \%$

Analysis of Variance

$\begin{array}{lccccc}\text { Source } & \text { DF } & \text { SS } & \text { MS } & F & P \\ \text { Regression } & 1 & 1,17 \mathrm{E}-03 & 1,17 \mathrm{E}-03 & 0,04 & 0,84 \\ \text { Error } & 13 & 3,59 \mathrm{E}-01 & 2,76 \mathrm{E}-02 & & \\ \text { Total } & 14 & 3,60 \mathrm{E}-01 & & & \end{array}$




\section{$\mathrm{CaCl}_{2}$ e CTC}

The regression equation is

$\mathrm{CaCl}_{2}=0.0697-0.000002$ CTC

$\begin{array}{ccccc}\text { Predictor } & \text { Coef } & \text { StDev } & \text { T } & \text { P } \\ \text { Constant } & 0.0697216 & 0,000266 & 262,13 & 0 \\ \text { CTC } & -0.00000190 & 3,58 \mathrm{E}-06 & -0,53 & 0,605\end{array}$

$S=0.0005206 \quad R-S q=2.1 \% \quad R-S q(\operatorname{adj})=0.0 \%$

Analysis of Variance

\begin{tabular}{lrrrrrr} 
Source & DF & \multicolumn{2}{c}{ SS } & MS & \multicolumn{2}{c}{$P$} \\
Regression & & 1 & $7,61 \mathrm{E}-03$ & $7,61 \mathrm{E}-03$ & 0,28 & 0,605 \\
Error & & 13 & $3,52 \mathrm{E}-01$ & $2,71 \mathrm{E}-02$ & & \\
Total & & 14 & $3,60 \mathrm{E}-01$ & & &
\end{tabular}

Unusual Observations

Obs CTC CaCl2 Fit StDev Fit Residual St Resid

$\begin{array}{llllllll}2 & 150 & 0.069000 & 0.069438 & 0.000335 & -0.000438 & -1.10 X\end{array}$

\section{$\mathrm{CaCl}_{2}$ e argila}

The regression equation is

$\mathrm{CaCl}_{2}=0.0697-0.000000$ argila

$\begin{array}{lcccc}\text { Predictor } & \text { Coef } & \text { StDev } & \text { T } & P \\ \text { Constant } & 0,069736 & 0,000255 & 273,3 & 0 \\ \text { argila } & -4,2 \mathrm{E}-07 & 6,7 \mathrm{E}-07 & -0,63 & 0,541\end{array}$

$S=0.0005184 \quad R-S q=2.9 \% \quad R-S q(\operatorname{adj})=0.0 \%$

Analysis of Variance

$\begin{array}{lccccc}\text { Source } & \text { DF } & \text { SS } & \text { MS } & F & P \\ \text { Regression } & 1 & 1,06 \mathrm{E}-02 & 1,06 \mathrm{E}-02 & 0,39 & 0,541 \\ \text { Error } & 13 & 3,49 \mathrm{E}-01 & 2,69 \mathrm{E}-02 & & \\ \text { Total } & 14 & 3,60 \mathrm{E}-01 & & & \end{array}$




\section{$\mathrm{CaCl}_{2}$ e ferro ditionito}

The regression equation is

$\mathrm{CaCl}_{2}=0.0697-0.000023 \mathrm{Fe}$ (ditionito)

Predictor Coef StDev $\quad$ T $\quad P$

$\begin{array}{lllll}\text { Constant } & 0.0697009 & 0,000188 & 370,81 & 0\end{array}$

Fe(ditio $\quad-0.00002297 \quad 3,03 E-05 \quad-0,76 \quad 0,461$

$S=0.0005149 \quad R-S q=4.2 \% \quad R-S q(\operatorname{adj})=0.0 \%$

Analysis of Variance

$\begin{array}{lccccc}\text { Source } & \text { DF } & \text { SS } & \text { MS } & F & P \\ \text { Regression } & 1 & 1,53 \mathrm{E}-02 & 1,53 \mathrm{E}-02 & 0,58 & 0,461 \\ \text { Error } & 13 & 3,45 \mathrm{E}-01 & 2,65 \mathrm{E}-02 & & \\ \text { Total } & 14 & 3,60 \mathrm{E}-01 & & & \end{array}$

\section{$\mathrm{CaCl}_{2}$ e Cd total}

The regression equation is

$\mathrm{CaCl}_{2}=0.0696+0.000034 \mathrm{Cd}$ total

\begin{tabular}{lrrrr} 
Predictor & Coef & StDev & \multicolumn{2}{r}{$P$} \\
Constant & 0,069563 & 0,000248 & 280,18 & 0 \\
Cd total & $3,39 \mathrm{E}-05$ & 0,000191 & 0,18 & 0,862
\end{tabular}

$\begin{array}{lllll}\text { Cd total } & 3,39 E-05 & 0,000191 & 0,18 & 0,862\end{array}$

$S=0.0005256 \quad R-S q=0.2 \% \quad R-S q(\operatorname{adj})=0.0 \%$

Analysis of Variance

\begin{tabular}{|c|c|c|c|c|c|c|c|}
\hline Source & DF & & SS & MS & $\mathrm{F}$ & $\mathrm{F}$ & \\
\hline Regression & & 1 & 8,75E-04 & 8,75E-04 & & 0,03 & 0,862 \\
\hline Error & & 13 & $3,59 E-01$ & $2,76 \mathrm{E}-02$ & & & \\
\hline Total & & 14 & $3,60 \mathrm{E}-01$ & & & & \\
\hline
\end{tabular}


Tabela 8. Coeficientes de correlação encontrados nas análises de regressão simples entre os três extratores convencionais, Mehlich 3, DTPA-TEA pH 7,3 e $\mathrm{CaCl}_{2} 0,01 \mathrm{~mol} \mathrm{~L}^{-1}$ com as variáveis independentes

\begin{tabular}{|c|c|c|c|c|c|c|}
\hline & argila & CTC & C & $\mathrm{pH} \mathrm{KCl} 1 \mathrm{~mol} \mathrm{~L}^{-}$ & $\mathrm{Fe}_{\mathrm{d}}$ & Cd Total \\
\hline$\overline{\text { Mehlich } 3}$ & $-0,08$ & 0,04 & 0,21 & $-0,27$ & $-0,16$ & 0,10 \\
\hline DTPA & $-0,73$ & $-0,35$ & $-0,25$ & $-0,47$ & $-0,65$ & $-0,40$ \\
\hline $\mathrm{CaCl}_{2}$ & $-0,17$ & $-0,14$ & 0,05 & $-0,03$ & $-0,20$ & 0,04 \\
\hline
\end{tabular}

Adotando-se um nível de significância geral de 10\% 
Regressão Múltipla: Mehlich 3 versus pH KCl; C; CTC; argila; Fed; Cd total

Alpha-to-Enter: 0,25 Alpha-to-Remove: 0,25

Response is Mehlich on 6 predictors, with $N=15$

No variables entered or removed

Regressão Múltipla: DTPA versus pH KCl; C; CTC; argila; Fed; Cd Total

Alpha-to-Enter: 0,25 Alpha-to-Remove: 0,25

Response is DTPA on 6 predictors, with $N=15$

$\begin{array}{cc}\text { Step } & 1 \\ \text { Constant } & 0,3489\end{array}$

argila $\quad-0,00046$

T-Value $\quad-3,81$

P-Value $\quad 0,002$

S $\quad 0,0930$

R-Sq $\quad 52,79$

R-Sq(adj) 49,15

C-p $\quad-0,3$

PRESS $\quad 0,151775$

$\mathrm{R}$-Sq(pred) $\quad 36,28$

Regressão Múltipla: $\mathrm{CaCl}_{2}$ versus pH KCl; C; CTC; argila; Fed; Cd Total

Alpha-to-Enter: 0,25 Alpha-to-Remove: 0,25

Response is $\mathrm{CaCl}_{2}$ on 6 predictors, with $\mathrm{N}=15$

No variables entered or removed 


\title{
Extração de Cd (Teste de Tukey)
}

\author{
General Linear Models Procedure \\ Class Level Information \\ Class Levels Values \\ SOLO $\quad 15 \quad 123456789101112131415$ \\ $\begin{array}{lll}\text { TRAT } & 3123\end{array}$
}

Number of observations in data set $=135$

Extração de Cd

General Linear Models Procedure

Dependent Variable: CdRAIZ

\begin{tabular}{|c|c|c|c|c|}
\hline Source & DF & Sum of Squares & F Valt & $\operatorname{Pr}>$ \\
\hline Model & 44 & 0.45581831 & 2.30 & 0.0004 \\
\hline Error & 90 & 0.40576476 & & \\
\hline Corrected Tot & 134 & 0.86158307 & & \\
\hline & juare & C.V. & CdRAIZ & Mean \\
\hline & 9047 & 8.614126 & 0.77 & 947949 \\
\hline Source & DF & Type I SS & F Value & $\operatorname{Pr}>\mathrm{F}$ \\
\hline SOLO & 14 & 0.10170465 & 1.61 & 0.0912 \\
\hline TRAT & 2 & 0.17018669 & 18.87 & 0.0001 \\
\hline SOLO*TRAT & 28 & 0.18392697 & 1.46 & 0.0940 \\
\hline Source & DF & Type III SS & F Value & $\operatorname{Pr}>\mathrm{F}$ \\
\hline SOLO & 14 & 0.10170465 & 1.61 & 0.0912 \\
\hline TRAT & 2 & 0.17018669 & 18.87 & 0.0001 \\
\hline SOLO*TRAT & 28 & 0.18392697 & 1.46 & 0.0940 \\
\hline
\end{tabular}




\section{Extração de Cd}

General Linear Models Procedure

Tukey's Studentized Range (HSD) Test for variable: CdRAIZ

NOTE: This test controls the type I experimentwise error rate, but generally has a higher type II error rate than REGWQ.

Alpha $=0.05 \mathrm{df}=90 \mathrm{MSE}=0.004508$

Critical Value of Studentized Range $=4.932$

Minimum Significant Difference $=0.1104$

Means with the same letter are not significantly different.

\begin{tabular}{|c|c|c|}
\hline Tukey Grouping & Mean & N SOLO \\
\hline$A$ & 0.82797 & 914 \\
\hline$A$ & 0.81892 & 912 \\
\hline$A$ & 0.81402 & 95 \\
\hline A & 0.81068 & 915 \\
\hline A & 0.79486 & 93 \\
\hline A & 0.78094 & 91 \\
\hline A & 0.77398 & 94 \\
\hline$A$ & 0.77217 & 97 \\
\hline A & 0.76902 & 911 \\
\hline A & 0.76811 & 96 \\
\hline A & 0.76443 & 913 \\
\hline A & 0.76393 & 92 \\
\hline A & 0.75894 & 910 \\
\hline A & 0.74681 & 99 \\
\hline A & 0.72743 & 98 \\
\hline
\end{tabular}




\section{Extração de Cd}

General Linear Models Procedure

Tukey's Studentized Range (HSD) Test for variable: CdRAIZ

NOTE: This test controls the type I experimentwise error rate, but generally has a higher type II error rate than REGWQ.

$$
\begin{gathered}
\text { Alpha }=0.05 \mathrm{df}=90 \mathrm{MSE}=0.004508 \\
\text { Critical Value of Studentized Range }=3.370 \\
\text { Minimum Significant Difference }=0.0337
\end{gathered}
$$

\begin{tabular}{|c|c|c|c|c|}
\hline \multirow{2}{*}{$\begin{array}{l}\text { Level c } \\
\text { SOLO }\end{array}$} & \multirow{2}{*}{$\begin{array}{l}\text { Level of } \\
\text { TRAT }\end{array}$} & & & \\
\hline & & $\mathrm{N}$ & Mean & \\
\hline 1 & 1 & 3 & 0.75708654 & 0.01516422 \\
\hline 1 & 2 & 3 & 0.83140413 & 0.15215373 \\
\hline 1 & 3 & 3 & 0.75432089 & 0.00000000 \\
\hline 2 & 1 & 3 & 0.75716203 & 0.00764749 \\
\hline 2 & 2 & 3 & 0.77987384 & 0.05191519 \\
\hline 2 & 3 & 3 & 0.75476259 & 0.00038253 \\
\hline 3 & 1 & 3 & 0.77023895 & 0.00989634 \\
\hline 3 & 2 & 3 & 0.85891589 & 0.05826873 \\
\hline 3 & 3 & 3 & 0.75542457 & 0.00076405 \\
\hline 4 & 1 & 3 & 0.71177461 & 0.00808491 \\
\hline 4 & 2 & 3 & 0.855 & 0.19 \\
\hline 4 & 3 & 3 & 0.75454174 & 0.00038253 \\
\hline 5 & 1 & 3 & 0.74373605 & 0.01688293 \\
\hline 5 & 2 & 3 & 0.94377569 & 0.17009163 \\
\hline 5 & 3 & 3 & 0.75454174 & 0.00038253 \\
\hline 6 & 1 & 3 & 0.72744271 & 0.03522287 \\
\hline 6 & 2 & 3 & 0.82233425 & 0.02548659 \\
\hline 6 & 3 & 3 & 0.75454174 & 0.00038253 \\
\hline 7 & 1 & 3 & 0.78013828 & 0.04556758 \\
\hline 7 & 2 & 3 & 0.78137725 & 0.06460954 \\
\hline 7 & 3 & 3 & 0.75498344 & 0.00000000 \\
\hline
\end{tabular}

Means with the same letter are not significantly different.

\begin{tabular}{cccc} 
Tukey Grouping & \multicolumn{3}{c}{ Mean } \\
A & 0.82969 & 45 & 2 \\
B & 0.75463 & 45 & 3 \\
B & & & \\
B & 0.75412 & 45 & 1
\end{tabular}




$\begin{array}{lcccc}8 & 1 & 3 & 0.72084835 & 0.02380109 \\ 8 & 2 & 3 & 0.70710678 & 0.00000000 \\ 8 & 3 & 3 & 0.75432089 & 0.00000000 \\ 9 & 1 & 3 & 0.72744271 & 0.03522287 \\ 9 & 2 & 3 & 0.75845069 & 0.04613928 \\ 9 & 3 & 3 & 0.75454174 & 0.00038253 \\ 10 & 1 & 3 & 0.72306567 & 0.02764160 \\ 10 & 2 & 3 & 0.79942101 & 0.07993166 \\ 10 & 3 & 3 & 0.75432089 & 0.00000000 \\ 11 & 1 & 3 & 0.75814870 & 0.08840719\end{array}$

Extração de Cd

General Linear Models Procedure

\begin{tabular}{lrrrr}
\multicolumn{2}{l}{$\begin{array}{l}\text { Level of } \\
\text { SOLO }\end{array}$} & $\begin{array}{c}\text { Level of } \\
\text { TRAT }\end{array}$ & \multicolumn{3}{c}{ N } & Mean & SD \\
11 & 2 & 3 & 0.79415715 & 0.06302085 \\
11 & 3 & 3 & 0.75476259 & 0.00038253 \\
12 & 1 & 3 & 0.87019599 & 0.13834160 \\
12 & 2 & 3 & 0.83222926 & 0.03304058 \\
12 & 3 & 3 & 0.75432089 & 0.00000000 \\
13 & 1 & 3 & 0.76001979 & 0.05962271 \\
13 & 2 & 3 & 0.77851949 & 0.02934471 \\
13 & 3 & 3 & 0.75476240 & 0.00076472 \\
14 & 1 & 3 & 0.75043099 & 0.01673291 \\
14 & 2 & 3 & 0.97870944 & 0.05649568 \\
14 & 3 & 3 & 0.75476259 & 0.00038253 \\
15 & 1 & 3 & 0.75403007 & 0.04645395 \\
15 & 2 & 3 & 0.92346089 & 0.21407938 \\
15 & 3 & 3 & 0.75454174 & 0.00038253
\end{tabular}

Tratamento 1: Mehlich 3

Tratamento 2: DTPA-TEA pH 7,3

Tratamento 3: $\mathrm{CaCl}_{2}$ 0,01 $\mathrm{mol} \mathrm{L}^{-1}$ 
Tabela 9. Cd extraído, média de três repetições, pelos diferentes extratores convencionais

\begin{tabular}{lccc}
\hline \multicolumn{1}{c}{ Solo } & Mehlich 3 & DTPA & $\mathrm{CaCl}_{2}$ \\
\hline LVj & $0,757 \mathrm{~b}$ & $0,831 \mathrm{a}$ & $0,754 \mathrm{~b}$ \\
LVef & $0,757 \mathrm{~b}$ & $0,779 \mathrm{a}$ & $0,754 \mathrm{~b}$ \\
LAw & $0,77 \mathrm{~b}$ & $0,858 \mathrm{a}$ & $0,755 \mathrm{~b}$ \\
PVAe & $0,711 \mathrm{~b}$ & $0,855 \mathrm{a}$ & $0,754 \mathrm{~b}$ \\
PVAd-1 & $0,743 \mathrm{~b}$ & $0,943 \mathrm{a}$ & $0,754 \mathrm{~b}$ \\
PVAd-2 & $0,727 \mathrm{~b}$ & $0,822 \mathrm{a}$ & $0,754 \mathrm{~b}$ \\
LVd & $0,78 \mathrm{~b}$ & $0,781 \mathrm{a}$ & $0,754 \mathrm{~b}$ \\
LVdf-1 & $0,72 \mathrm{~b}$ & $0,707 \mathrm{a}$ & $0,754 \mathrm{~b}$ \\
LVdf-2 & $0,727 \mathrm{~b}$ & $0,758 \mathrm{a}$ & $0,754 \mathrm{~b}$ \\
LVAd-1 & $0,723 \mathrm{~b}$ & $0,799 \mathrm{a}$ & $0,754 \mathrm{~b}$ \\
LVAd-2 & $0,758 \mathrm{~b}$ & $0,794 \mathrm{a}$ & $0,754 \mathrm{~b}$ \\
LVAw & $0,87 \mathrm{~b}$ & $0,832 \mathrm{a}$ & $0,754 \mathrm{~b}$ \\
Nvef & $0,76 \mathrm{~b}$ & $0,778 \mathrm{a}$ & $0,754 \mathrm{~b}$ \\
RQo & $0,75 \mathrm{~b}$ & $0,978 \mathrm{a}$ & $0,754 \mathrm{~b}$ \\
SXd & $0,754 \mathrm{~b}$ & $0,923 \mathrm{a}$ & $0,754 \mathrm{~b}$ \\
\hline
\end{tabular}

Médias seguidas de mesma letra, nas linhas, não diferem entre si pelo teste de Tukey a $1 \%$ 


\section{REFERÊNCIAS BIBLIOGRÁFICAS}

ABREU, C.A.; ABREU, M.F.; BERTON, R.S. Análise química de solo para metais pesados. Revista Brasileira de Ciência do Solo, v.2, 2002. /No prelo/

ABREU, C. A. de; ABREU, M.F. de. Micronutrientes e metais pesados em solos: monitoramento de áreas agrícolas. In: REUNIÃO BRASILEIRA DE FERTILIDADE DO SOLO E NUTRIÇÃO DE PLANTAS, 23.; REUNIÃO BRASILEIRA SOBRE MICORRIZAS, 7.; SIMPÓSIO BRASILEIRO DE MICROBIOLOGIA DO SOLO, 5.; REUNIÃO BRASILEIRA DE BIOLOGIA DO SOLO, 2., Caxambu, 1998. Resumos. Lavras: UFLA;SBCS;SBM , 1998. $455 p$.

ABREU, M.F. de. Extração e determinação simultânea por emissão em plasma de nutrientes e elementos tóxicos em amostras de interesse agronômico. Campinas, 1997. 132p. Tese (Doutorado) - Universidade Estadual de Campinas.

ABREU, M.F.de; BERTON, R.S.; ANDRADE, J.C. de. Comparison of methods to evaluate heavy metals in organic wastes. Communications in Soil Science Plant Analysis, v.27, n.5/8, p.1125-1135, 1996.

ALI, M.A.; DZOMBAK, D.A. Effects of simple organic acids on sorption of $\mathrm{Cu}^{2+}$ and $\mathrm{Ca}^{2+}$ on goethite. Geochimica Cosmochimica Acta, v.60, p.291-304, 1996.

ALLOWAY, B. J. The origins of heavy metals in soils. In: ALLOWAY, B. J. Heavy metals in soils. New York: John Wiley, 1990. p. 29-39.

AMACHER, M.C.; KOTUBY-AMACHER, J.; SELIM, H.M.; ISKANDAR, I.K. Retention and release of metals by soils - evaluation of several models. Geoderma, v.38, p.131-154, 1986.

AMARAL SOBRINHO, N.M.B.; COSTA, L.M.; OLIVEIRA, C.; VELLOSO, A.C.X. Metais pesados em alguns fertilizantes e corretivos. Revista Brasileira de Ciência do Solo, v.16, p.271-276, 1992. 
BARROW, N.J. The reaction of plant nutrients and pollutants with soil. Australian Journal of Soil Research, v.27, p.475-492, 1989.

BARROW, N.J. Reactions of anions and cations with variable-charge soils. Advances in Agronomy, v.38, p.183-230, 1985.

BOLT, G.H., DE BOODT, M.F., HAYES, M.H.B.; MCBRIDE, M.B. Interactions at the Soil Colloid - Soil solution Interface. Belgium. State University of Ghent. 1986. p.278-292.

BRASIL. Ministério da Saúde. Divisão Nacional de Vigilância Sanitária de Alimentos. In: ASSOCIAÇÃO BRASILEIRA DAS INDÚSTRIAS DE ALIMENTAÇÃO. Compêndio da legislação de alimentos. São Paulo: ABIA, 1985. 1v.

CAMARGO, O. A.; MONIZ, A.C.; JORGE, J.A.; VALADARES, J.M.S. Métodos de análise química, mineralógica e física de solos do Instituto Agronômico de Campinas. Campinas: Instituto Agronômico, 1986. 94p. (Boletim Técnico, 106).

CASTRO NETO, P.P. Controle de resíduos sólidos industriais no Estado de São Paulo. Limpeza Pública, v.24, n.1, p.3-11, 1985.

CETESB. Aplicação de lodos de sistemas de tratamento biológico em áreas agrícolas - critérios para projeto e operação. São Paulo: CETESB, 1999. 32p. (Manual Técnico P4. 230 de agosto/99)

CHEN, B.; SHAN, X.; QIAN, J. Bioavailability index for quantitative evaluation of plant availability of extractable soil trace elements. Plant and Soil, v.186, p.275-283, 1996.

CIESLINSKI, G.; VAN REES, K.C.J.; SZMIGIELSKA, A.M.; KRISHNAMURTI, G.S.R.; HUANG, P.M. Low-molecular-weight organic acids in rhizosphere soils of durum wheat and their effect on cadmium bioaccumulation. Plant and Soil, v.203, p.109-117, 1998.

COKER, E.G.; MATTHEWS, P.J. Metals in sewage sludge and their potential effects in agriculture. Water Science Technology, v.15, p.209-225, 1983.

CUNHA, R.C. DE A., CAMARGO, O.A.; KINJO, T. Aplicação de três isotermas na adsorção de zinco em oxissolos, alfissolos e ultissolos. Revista Brasileira de Ciência do Solo, v.18, p.15-20, 1994. 
DIAS, N.M.P., ALLEONI, L.R.F, CASAGRANDE, J.C.; CAMARGO, O.A. Isotermas de adsorção de cádmio em solos ácricos. Revista Brasileira de Engenharia Agrícola e Ambiental, v.5, n.2, p.229-234, 2001.

DIAS, N.M.P. Adsorção de cádmio em solos ácricos. Piracicaba, 1999. 100p. Dissertação (Mestrado) - Escola Superior de Agricultura Luiz de Queiroz, Universidade de São Paulo.

EMBRAPA. Sistema brasileiro de classificação de solos. Brasília: Embrapa Produção de Informação, 1999. 412p.

EMMERICH, W.E.; LUND, L.J.; PAGE, A.L.; CHANG, A.C. Solid phase forms of heavy metals in sewage sludge-treated solils. Journal of Environmental Quality, v.11, p.178-181, 1982.

EVANGELOU, V.P. Environmental Soil and Water Chemistry: principles and applications. New York. 1998, 221-223p.

GADDE, R.R.; LAITINEN, H.A. Studies of heavy metal adsorption by hydrous iron and manganese oxides. Analytical Chemistry, v.46, n.13, p.20222026, 1974.

GARCIA-MIRAGAYA, J.; PAGE, A.L. Sorption of trace quantities of cadmium by soils with different chemical and mineralogical compositium. Water Air and Soil Pollution, v.9, p.289-299, 1978.

GARCIA-MIRAGAYA, J.; PAGE, A.L. Influence of ionic strength and inorganic complex formation on the sorption of trace amounts of $\mathrm{Cd}$ by montmorillonite. Soil Science Society of America Journal, v.40, p.658663, 1976.

GARCIA-MIRAGAYA, J. Sorption and desorption of Cadmium by Soils and Soil Materials. Riverside, 1975. 110p. Dissertation (M.S.) - University of California.

GUILHERME, L.R.G.; ANDERSON, S.J. Copper sorption kinetics in two oxiderich soil (Oxisols): effect or phosphate pretreatment. In: JENNE E.A. (Ed.) Sorption of metals by earth materials: factors, rates, mechanisms, and model applications. - s.l. Academic Press, 1997. 1v.

GUILHERME, L.R.G., LIMA, J.M.; ANDERSON, S.J. Efeito do fósforo na adsorção de cobre em horizontes A e B de latossolos do Estado de Minas Gerais. In: CONGRESSO BRASILEIRO DE CIÊNCIA DO SOLO, 25., Viçosa, 1995. Resumos. Viçosa: SBCS;UFV, 1995. p.316-318p. 
GODO, G.H.; REISENAUER, H.M. Plant effects on soil manganese availability. Soil Science Society of America Journal, v.44, p.993-995, 1980.

GUNN, A.M.; WINNARD, D.A.; HUNT, D.T.E. Trace metal speciation in sediments and soils. In: KRAMER, J.R.; ALLEN, H.E. (Ed.) Metal speciation theory analysis and application. Chelsea, Lewis Publ., 1988. p. 261-293.

HADDAD, K.S.; EVANS, J.C. Assessment of chemical methods for extracting zinc, manganese, copper and iron from new south wales soils. Communications in Soil Science and Plant Analysis, v.24, n.1/2, p.2944, 1993.

HALL, J. Standardising and the management of biosolids the international experience. In: SEMINÁRIO SOBRE GERENCIAMENTO DE BIOSSÓLIDOS DO MERCOSUL, 1., Curitiba, 1998. Anais. Curitiba: SANEPAR; ABEAS, 1998. p.113-122.

HANI, H.; GUPTA, S. Reasons to use neutrol salts solutions to assess the metal impact on plant and soil. In: LESCHBER, R.; DAVIES, R.D.; L'HERMITÉ, P. Chemical methods for assessing bioavailability metals in sludge and soils. London: Elsevier, 1985. p.42-48.

HAO, A.U.; BATES, T.E.; SOON, Y.K. Comparasion of extractants for plant available zinc, cadmium, nickel and copper in contamined soils. Soil Science Society of America Journal, v. 44, p.772-777, 1980.

HOGG, D.S.; MCLAREN, R.G.; SWIFT, R.S. Desorption of copper from some New Zealand soils. Soil Science Society of America Journal, v.57, p.361-366, 1993.

HOODA, P.S. Plant availability of heavy metals in soils previously amended with heavy applications of sewage sludge. Journal of Science of Food and Agriculture, v.73, p.446-454, 1997

HUE, N.V.; SILVA, J.A.; ARIFIN, R. Sewage sludge-soil interactions as measure by plant and soil chemical composition. Journal of Environmental Quality, v.17, p.384-390, 1988.

KABATA-PENDIAS, A.; PENDIAS, H. Trace elements in soils and plants. Flórida: CRC Press, 1984. 315p. 
KELLING, K.A.; KEENEY, D.R.; WALSH, L.M.; RYAN, J.A. A field study of the agricultural use of sewage sludge: III. Effect on uptake and extractability of sludge-born metals. Journal of Environmental Quality, v.6, p.352-358, 1977.

KIEKENS, L.; COTTENIE, A. Principles of investigation on the mobility and plant uptake of heavy metals. In: LESCHBER, R; DAVIES, R.D.; L'HERMITÉ, P. Chemical methods for assessing bioavailability metals in sludge and soils. London: Elsevier, 1985. p. 32-41.

KING, L.D. Retention of metals by several soils of the Southeastern United States. Journal of Environmental Quality, v.17, n.2, p.239-246, 1988.

KORT, N.E.; SKOPP, J.; FULLER, W.H.; NIEBLA, E.E.; ALESII, B.A. Trace element movement inf soils. Influence of soil physical and chemical properties. Soil Science, v.122, n.6, p.350-359, 1976.

KRISHNAMURTI, G.S.R.; SMITH, L.H.; NAIDU, R. Method for assessing plantavailable cadmium in soils. Australian Journal of Soil Research, v.38, p.823-836, 2000.

KRISHNAMURTI, G.S.R.; CIESLINSKI, G.; HUANG, P.M.; VAN REES, K.C.J. Kinetics of Cadmium Release from Soils as Influenced by Organic Acids: implication in Cadmium Availability. Journal of Environmental Quality, v.26, p.271-277, 1997.

LEVY. D.B.; BARBARICK, K.A.; SIEMER, E.G.; SOMMERS, L.E. Distribuition and partitioning of trace metals in contamined soils near Leadville, Colorado. Journal of Environmental Quality, v. 22, n.4, p.731-737, 1992.

LINDSAY, W.L. Lead. In: Lindsay, W.L. Chemical equilibria in soils. New York : Wiley-Interscience, 1979. 449p.

MAIZ, I; ESNAOLA, M. V.; MILLÁN, E. Evaluation of heavy metal availability in contamined soils by a short sequential extraction procedure. Science of Total Environment, v.206, p.107-115, 1997.

MATOS, A.T. Fatores de retardamento e coeficientes de dispersão-difusão do zinco, cádmio, cobre e chumbo em solos do município de Viçosa-MG. Viçosa, 1995. 110p. Tese (Doutorado) - Universidade Federal de Viçosa.

McBRIDE, M.B. Environmental chemistry of soils. New York: Oxford University Press, 1994. 406p. 
McBRIDE, M.B. Reactions controlling heavy metal solubility in soils. Advances in Soil Science, v.10, p.1-56, 1989.

McGRATH, S.P.; CEGARRA, J. Chemical extractability of heavy metals during and after long-term application of sewage sludge to soil. Journal of Soil Science, v.43, p.313-321, 1992.

McLAUGHLIN, M.J. ; ZARCINAS, B.A.; STEVENS, D.P.; COOK, N. Soil testing for heavy metals. In: INTERNATIONAL CONFERENCE ON SOIL TESTING AND PLANT ANALYSIS, 6., Brisbane, 1999. Brisbane: - s. ed., 1999. 1v.

MEHLICH, A. Mehlich 3 soil test extractant. A modification of Mehlich 2 extractant. Communications in Soil Science and Plant Analysis, v.15, p.1409-1416, 1984.

MENCH, M.; MARTIN, E. Mobilization of cadmium and other metals from two soils by root exudates of Zea mays L., Nicotiana tabacum L., Nicotiana rustica L. Plant and Soil, v.132, p.187-196, 1991.

MENK, J.R.F.; IGUE, T. Relacionamento de dados de solos entre métodos analíticos: o caso da análise granulométrica. Revista Brasileira de Ciência do Solo, v.16, p.143-152, 1992.

MERCKX, R; VANGINKEL, J.H.; SINNAEVE, J.; CREMERS, A. Plant-induced changes in the rhizosphere of maize and wheat. II Complexation of cobalt, zinc and manganese in the rhizosphere of maize and wheat. Plant and Soil v.96, p.95-108, 1986.

MINER, G.S.; GUTIERREZ, R.; KING, L.D. Soil factors affecting plant concentrations of cadmium, copper, and zinc on sludge-amended soils. Journal of Environmental Quality, v.26, p.989-994, 1997.

MONTERROSO, C.; ALVAREZ, E.; MARCOS, M.L.F. Evaluation of mehlich 3 reagent as a multielement extractant in mine soils. Land Degradation Development, v.10, p.35-47, 1999.

NRIAGU, J.O.; PACYNA, J.M. Quantitative assessment of worldwide contamination of air, water and soils with trace metals. Nature, v.333, p.134139, 1988.

OLIVEIRA, J.B. Solos da Folha e Município de Guaíra. Campinas: Instituto Agronômico, 1995. 127p. (Boletim Científico, 33) 
OLIVEIRA, J.B.; PRADO, H. Levantamento pedológico semidetalhado do Estado de São Paulo: Quadrícula de Ribeirão Preto. II. Memorial Descritivo. Campinas: Instituto Agronômico, 1984. 133p. (Boletim Científico, 7).

OLIVEIRA, J.B.; PRADO, $\mathrm{H}$. Levantamento pedológico semidetalhado do Estado de São Paulo: Quadrícula de São Carlos. Il. Memorial descritivo. Campinas: Instituto Agronômico, 1984. 188p. (Boletim Técnico, 98).

OLIVEIRA, J.B.; MENK, J.R.F.; BARBIERI, J.L., ROTTA, C.L.; TREMOCOLDE, W. Levantamento pedológico semidetalhado do Estado de São Paulo: Quadrícula de Araras. Campinas: Instituto Agronômico, 1982. 180p. (Boletim Técnico, 71).

OMAE, S. Adsorção de cádmio em solo podzólico vermelho amarelo-orto, glei húmico da região do vale do Ribeira-SP e terra roxa estruturada do município de Piracicaba-SP. Piracicaba, 1984. 41p. Dissertação (Mestrado) - Escola Superior de Agricultura Luiz de Queiroz, Universidade de São Paulo.

PADMANABHAM, M. Comparative study of the adsorption-desorption behavior of copper (II), zinc (II), cobalt (II) and lead (II) at the goethite-solution interface. Australian Journal of Soil Research, v.21, p.515-525. 1983.

PARKER, D.R.; NORWELL, W.A.; CHANEY, R.L. Geochem-PC: A chemical speciation program for IBM and compatible personal computers. Soil Science Society of America Journal, v.42, p.253-269, 1995. Special Publication.

PEREIRA NETO, J. T. Alguns aspectos sobre o estado da arte do gerenciamento dos resíduos sólidos no Brasil. In: SIMPÓSIO LUSO BRASILEIRO DE ENGENHARIA SANITÁRIA E AMBIENTAL, 5., Lisboa, 1992. Anais. Lisboa: SILUBESA, 1992. p.397-418.

PETRUZZELLI, G.; GUIDI, G.; LUBRANO, L. lonic strength effect on heavy metal adsorption by soil. Commumications in Soil Science and Plant Analysis, v.16, v.9, p.971-986, 1985.

PICKERING, W. F. Selective chemical extraction of soil components and bound metal species. CRC - Critical Reviews in Analytical Chemistry, p.233-266, 1981.

POMBO, L.C.A. Sorção de cádmio em solos do Estado do Rio Grande do Sul. Revista Brasileira de Ciência do Solo, v.19, n.1, p.19-24, 1995. 
RAIJ, B. V.; CANTARELLA, H.; QUAGGIO, J.A.; FURLANI, A.M.C. Recomendações de adubação e calagem para o Estado de São Paulo do Instituto Agronômico de Campinas. Campinas: Instituto Agronômico, 1997. 285p. (Boletim Técnico, 100)

RAIJ, B.V. Fertilidade do solo e adubação. Piracicaba: Potafos, 1991. 343p.

ROCA, J.; POMARES, F. Prediction of available heavy metals by six chemical extractants in a sewage sludge-amended soil. Communications in Soil Science and Plant Analysis, v.22, n.19/20, p. 2119-2136, 1991.

RHEINHEIMER, D. S.; ANGHINONI, I.; CONTE, E. Dessorção de fósforo em sistemas de manejo de solo. In: REUNIÃO BRASILEIRA DE FERTILIDADE DO SOLO E NUTRIÇÃO DE PLANTAS, 23.; REUNIÃO BRASILEIRA SOBRE MICORRIZAS, 7.; SIMPÓSIO BRASILEIRO DE MICROBIOLOGIA DO SOLO, 5.; REUNIÃO BRASILEIRA DE BIOLOGIA DO SOLO, 2., Caxambu, 1998. Resumos. Lavras: UFLA;SBCS;SBM , 1998. 455p.

SADOVNIKOVA, L. K.; ZYRIN, N. G. Indices of soil pollution by heavy metals used for soil monitoring. Sovietic Soil Science, v.17, n.6, p. 58-63, 1986.

SAS INSTITUTE. The SAS system for windows: release 6.11. Cary, 1996. 7p.

SINGH, S.S. Sorption and release of cadmium in some canadian soils. Canadian Journal of Soil Science, v.59, p.119-30, 1979.

SPOSITO, G. The chemistry of soils. New York: Oxford University Press. 1989. 1v.

SPOSITO, G.; LUND, L.J.; CHANG, A.C. Trace metal chemistry in acid-zone field soils amended with sewage sludge. I. Fractionation of $\mathrm{Ni}, \mathrm{Cu}, \mathrm{Zn}, \mathrm{Cd}$ and $\mathrm{Pb}$ in solid phases. Soil Science Society of America Journal, v.46, p.260264, 1982.

STENTIFORD, E. I. The compost process applied to sewage sludge and source separated refuse. - s.I: EEC, 1992. 192p.

TAVARES, T. M., CARVALHO, F. M. Avaliação da exposição de populações humanas a metais pesados no ambiente: exemplos do recôncavo baiano. Química Nova, v. 5, n. 2, p.147-153, 1992.

TOMÉ JR., J.B. Manual para interpretação de análise de solo. Guaíba: Agropecuária, 1997. 247p. 
XIU H.; TAYLOR, R.W.; SHUFORD, J.W.; TADESSE, W.; ADRIANO, D.C. Comparison of extractants for available sludge-borne metals - a residual study. Water Air and Soil Pollution, v.57/8, p913-922, 1991.

WOLT, J.D. Soil solution chemistry: applications to environmental science and agriculture. New York: John Wiley, 1994. 345p. 